\title{
FORMAÇÃO METAMÓRFICA DE CORONAS EM ROCHAS DOS COMPLEXOS MÁFICO-ULTRAMÁFICOS DE MANGABAL I E II, GOIÁS
}

\author{
MARIA A.F. CANDIA*, RAINER A. SCHULTZ-GÜTLLER* e JOSÉ C. GASPAR**
}

\begin{abstract}
METAMORPfIIC FORMATION OF CORONAS IN ROCKS OF THE MANGABAL I AND II MAFIC-ULTRAMAFIC COMPLEX, GOIÁS. Coronas of orthopyroxene, pargasitic amphibole and spinel occur between olivine and plagioclase in metaperidotites, feldspathic metaharzburgites and meta-olivine gabbronorites of the two small ultramafic complexes Mangabal I e Mangabal II Geological, textural and phase petrological evidence indicate that corona formation was contemporaneous with a thermal event producing more hydrated paragenesis in other parts of the complex pointing to a metamorphic overprint under high grade conditions. The different stages of corona formation and the development of the more hydrated paragenesis (clinochlore, orthopyroxene, magnesium hornblende) could be explained by changes in the composition of the fluid phase under virtually similar P-T conditions. Thermochemical calculations for chemically closed systems and isochores of $\mathrm{CO}_{2}$, as determined from fluid inclusions, point to about $750^{\circ} \mathrm{C}$ and 6 to $7 \mathrm{kbar}$ as P-T conditions of metamorphism.
\end{abstract}

Keywords: Corona, mafic-ultramafic complexes, metamorphic processes, fluid phase.

\begin{abstract}
RESUMO Neste trabalho são investigadas as coronas constituídas por ortopiroxênio, anfíbólio pargasítico e espinélio que se desenvolvem entre olivina e plagioclásio, em metaperidotitos, metaharzburgitos e metaolivina gabronoritos dos complexos máfico-ultramáficps de Mangabal I e II, em Goiás. As evidências geológicas, petrográficas, texturais e químico/mineralógicas indicam que a formação das coronas é contemporânea e relacionada a um evento térmico individualizado no tempo que afetou as rochas dos complexos, marcando reequilíbrios metamórficos de alto grau. A presença de rochas com coronas em diferentes estágios de evolução, coexistentes com rochas portadoras de paragêneses mais hidratadas (associações com clorita, ortopiroxênio, anfibólio), é interpretada como decorrente de variações na fase fluida quando dos reequilíbrios mineralógicos, todos estabelecidos sob as mesmas condições de temperatura e pressão. A elaboração termodinâmica (cálculos termoquímicos) para sistema fechado e as isócoras de $\mathrm{CO}_{2}$, determinadas a partir de dados de inclusões fluidas, fornecem condições de temperatura de $750^{\circ} \mathrm{C}$ e 6 a 7 kbar de pressão total para o metamorfismo que atuou na área.
\end{abstract}

Palavra-chaves: Coronas, complexos máfíco-ultramáficos, processos metamórficos, fase fluida.

INTRODUÇÃO A presença de coronas entre olivina e plagioclásio, constituídas por ortopiroxênio, anfibólio e espinélio simplectítico, é freqüentemente descrita em rochas gabróicas, em terrenos de fácies granulito e anfibolito, tendo sido objeto de estudo de diversos pesquisadores como Murthy (1958), Griffin \& Heier (1973), Gardner \& Robins (1974), Miller (1974), Grieve \& Gittins (1975), Sapountzis (1975), Esbensen (1978), Lamoen (1979), Hamlyn (1980), Emmett (1982), Mongkoltip \& Ashworth (1983), entre outros.

De modo geral, há consenso em que as coronas formam-se por processos subsólidus, através de difusão iônica de elementos em presença de fase fluida no sistema. Modelos alternativos são, entretanto, propostos no que concerne ao desenvolvimento das coronas, ou seja, se este se processaria em sistema aberto ou em sistema fechado. As divergências persistem sobre a origem da corona: se produto de recristalização metamórfica ou se sua formação seria devida a processos deutéricos e pós-magmáticos.

Este trabalho tem por objetivo analisar e interpretar as coronas que ocorrem em rochas dos complexos de Mangabal leu, dois pequenos complexos máfico-ultramáficos localizados no centro sul de Goiás. Nestes corpos, as coronas desenvolvem-se em dois tipos litológicos, um ultramáfico, outro gabróico, e podem ser observadas em diferentes estágios de evolução.

Em função dos dados obtidos, são discutidas as evidências químico-mineralógicas que viabilizam o desenvolvimento das coronas em sistema fechado. Sua formação, pela geologia e petrologia dos complexos, é vinculada aos processos metamórficos que atuaram na área.
MANGABAL I E II - ASPECTOS GEOLÓGICOS E PETROGRÁFICOS GERAIS Mangabal I e II são dois complexos máfico-ultramáficos localizados no centro sul do Estado de Goiás, próximo à cidade de Sanclerlândia. Os corpos distam cerca de $3 \mathrm{~km}$ entre si e se encaixam em terrenos granito-gnáissicos do complexo basal goiano (Almeida 1968). Embora seu contexto geológico ainda não se encontre devidamente estabelecido, são tentativamente correlacionados a corpos sin-orogenéticos em cadeias dobradas (Candia 1983, Nilson 1984)

Os complexos apresentam-se deformados e metamorfisados, entretanto ainda preserva feições relacionáveis às de corpos acamadados, formados por processos de fracionamento magmático. A seqüência estratigráfica magmática original é interpretada em função das feições texturais e químico/mineralógicas das fases reliquiares. Mangabal I apresenta uma seqüência basal, ultramáfica, de peridotitos feldspáticos; uma intermediária, de olivina gabronoritos, à qual se superpõe a seqüência de gabronoritos. Em Mangabal II, a seqüência basal, ultramáfica, é constituída por harzburgitos e bronzititos feldspáticos e a seqüência máfica é representada por olivina gabronoritos semelhantes aos de Mangabal I. Os processos tectônicos subseqüentes causaram deformação e inversão das unidades litológicas dos complexos, sendo responsáveis pela atual configuração dos corpos. As paragêneses metamórficas desenvolvidas nos diferentes tipos petrográficos originais indicam que os complexos tiveram semelhante evolução pós-magmática (Candia 1983, Candia \& Girardi 1985)

\footnotetext{
* Departamento de Mineralogia e Petrologia, Instituto de Geociências, Universidade de São Paulo, Caixa Postal 20899, CEP 01498, São Paulo, SP, Brasi ** Departamento de Mineralogia e Petrologia, Instituto Geociências, Fundação Universidade de Brasília, Campus Universitário, Asa Norte, CEP 70910, Brasília, DF, Brasil
} 


\section{Litologias portadoras de coronas - termos ígneos re-} liquíares e respectivos equivalentes recristalizados

As litologias de interesse neste estudo restringem-se aos metaperidotítos/metaharzburgitos feldspáticos (litologias ultramáficas) e aos metaolivina gabronoritos (litologias máficas), rochas originalmente portadoras de olivina e plagioclásio de derivação ígnea, fases minerais entre as quais ocorre o desenvolvimento das coronas. As características desses tipos petrográficos dos termos ígneos reliquiares aos respectivos equivalentes recristalizados são descritas a seguir, com base nos dados petrográficos e químicos de Candia (1983).

Termos ígneos reliquiares Embora os termos petrográficos com feições ígneas reliquiares já mostrem desenvolvimento de coronas, suas características originais podem ser interpretadas nas amostras com coronitização incipiente. Na descrição destes termos, o prefixo meta é abstraído.

Os peridotitos feldspáticos correspondem a cumulates (conforme terminologia de Wager et al. 1960, Irvine 1982) com olivina e cromo espinélio como fases cumulus, e plagioclásio, ortopiroxênio e clinopiroxênio como fases intercumulus principais. Os harzburgitos feldspáticos são cumulatos similares, porém com predominância de ortopiroxênio no material intercumulus.

Os olivina-gabronoritos são olivina-plagioclásio cumulatos, tendo estas duas fases como minerais cumulus e ortopiroxênio e clinopiroxênio como fases intercumulus principais.

Termos coroniticos As coronas mostram desenvolvimento semelhante, seja nas litologias ultrarnáficas, seja nas máficas, e se formam quando olivina e plagioclásio encontram-se em contato. A corona é constituída por uma camada interna, mais próxima à olivina, formada por pequenos cristais prismáticos de ortopiroxênio dispostos radialmente ao núcleo da olivina, e por uma faixa mais externa, formada por anfibólio pargasítico, fibroso, que se estende do ortopiroxênio até o plagioclásio, contendo inclusões simplectíticas de espinélio verde, mais abundantes quanto mais próximo ao plagioclásio (Fotomicrografia 1).

Nos peridotitos/harzburgitos feldspáticos, as coronas mais incipientes ocorrem nos termos com feições as mais reliquiares. Com a evolução da corona, as faixas de ortopiroxênio e de anfibólio simplectítico se expandem, enquanto a porcentagem modal do plagioclásio diminui e este apresenta-se turvo. Nas litologias ultrarnáficas, a corona evolui até consumir totalmente o plagioclásio. Até o estágio evolutivo em que o plagioclásio ainda está presente, as rochas foram designadas de metaperidotitos/harzburgitos coroníticos. Nas amostras nas quais o plagioclásio foi totalmente consumido, as feições texturais são modificadas: os ortopiroxênios que bordejam a olivina tomam-se granulares, o mesmo ocorrendo com o anfibólio que, liberado das inclusões simplectíticas, apresenta-se como massa granular, e o espinélio, liberado do anfibólio, ocorre em discretos grãos individualizados, mais abundantes na parte mais externa da corona. As rochas, neste estágio, foram designadas de metaperidotitos, harzburgitos com espinélio, sendo comum a ocorrência de carbonato (dolomita) associado ao espinélio (Fotomicrografia 2).

Nos olivina gabronoritos, a estruturação da corona é semelhante. As coronas mais incipientes são vistas nos termos com feições magrnáticas reliquiares. Com sua evolução, as faixas de ortopiroxênio cpronítico e de anfibólio simplectítico se alargam e o plagioclásio original apresenta-se intensamente turvo, enquanto, próximo à corona, observa-se plagioclásio recristalizado, límpido. A corona evolui até o desaparecimento da olivina. Enquanto a olivina é fase presente na corona, as rochas foram designadas de meta-olivina gabronoritos coroníticos. Com a transformação da olivina, passa-se a observar, em seu lugar, um agregado central de discretos cristais granulares de ortopiroxênio, bordejado por ampla faixa de anfibólio granular. Liberado das inclusões simplectíticas, espinélio verde passa então a ocorrer em grãos individualizados, mais abundantes na parte mais externa da corona. Nesse estágio, as rochas foram designadas de metaolivina gabronoritos com espinélio. Os plagioclásios próximos às coronas apresentam-se recristalizados, límpidos; os reliquiares podem, eventualmente, apresentar turvamente e reter feições magrnáticas.

As demais fases minerais de derivação magmática eventualmente presentes na associação original destes tipos petrográficos (ortopiroxênios, cünopiroxênios intercumulus, espinélios com cromo, etc...) não apresentam modificações texturais/composicionais simultâneas ao desenvolvimento das coronas, mantendo suas características originais.

Equivalentes recristalizados não-coroníticos As rochas com recristalização mais intensa mostram uma modificação textural e mineralógica global, envolvendo todas as fases minerais preexistentes. A estruturação coronítica é totalmente obliterada.

Nos litotipos ultramáficos, desenvolve-se a associação olivina, ortopiroxênio, anfibólio (magnésio-hornblenda) e clorita (clinocloro), sendo designadas de metaperidotitos/harzburgitos com clorita e mostrando texturas granoblásticas (Fotomicrografia 3).

Os litotipos máficos passam a metaolivina gabronoritos, gerando a associação plagioclásio (andesina) - hornblenda (magnésio-hornblenda) e ortoanfibólio (gedrita), com texturas granoblásticas (Fotomicrografia 4).

Nos complexos, a transição dos termos mais recristalizados (que correspondem às associações mais hidratadas), para os coroníticos ou magmáticos reliquiares, é relativamente rápida. De modo geral, observa-se que os termos mais recristalizados são mais abundantes nas zonas mais externas e nas partes mais deformadas dos corpos, indicando que sua formação é vinculada preferencialmente às áreas onde houve maior ingresso de fase fluida.

QUIMISMO MINERAL As características químicas das fases minerais de interesse nas diferentes associações consideradas neste trabalho (Tab. 1) são comentadas a seguir (a listagem com os dados analíticos pode ser solicitada aos autores).

As análises foram realizadas, em parte, utilizando microssonda eletrônica ARL modelo EMX-SM do Instituto de Geociências da USP, e, em parte, em equipamento ARL-EMX automatizado da Universidade de Chicago - EUA.

Olivinas Nos litotipos ultramáficos, a composição química da olivina varia de $\mathrm{Fo}_{83}$ alcançando $\mathrm{Fo}_{71}$ nos metaolivina gabronoritos coroníticos. A variação dos elementos menores $(\mathrm{MnO}, \mathrm{NiO}, \mathrm{CaO})$ mostra valores concordantes aos citados por Simkin \& Smith (1970) e Brown (1980) para olivinas de rochas plutônicas; a variação de $\mathrm{NiO}$ é decrescente (de 0,32 a $0,13 \%$ em peso) e a de $\mathrm{MnO}$ é crescente (de 0,21 a $0,33 \%$ em peso) devido ao aumento da molécula faialítica na olivina. $\mathrm{O}$ conteúdo de $\mathrm{CaO}$ é geralmente inferior a $0,5 \%$ em peso.

As olivinas não apresentam zoneamento, tendo composição constante na seção analisada. Da mesma forma, olivinas não-coroníticas (que não desenvolveram coronas por não estarem em contato com plagioclásio) e olivinas coroníticas mostram igual composição na secção.

Ortopiroxênios Os ortopiroxênios de associações coroníticas e com espinélio são essencialmente ferro-magnesianos, tendo composição constante na corona. A relação $\mathrm{Fe} / \mathrm{Mg}$ dos ortopiroxênios mostra nítida correspondência com a composição da olivina associada (Fig. 1). $\mathrm{O}$ teor em $\mathrm{Al}_{2} \mathrm{O}_{3}$ varia 


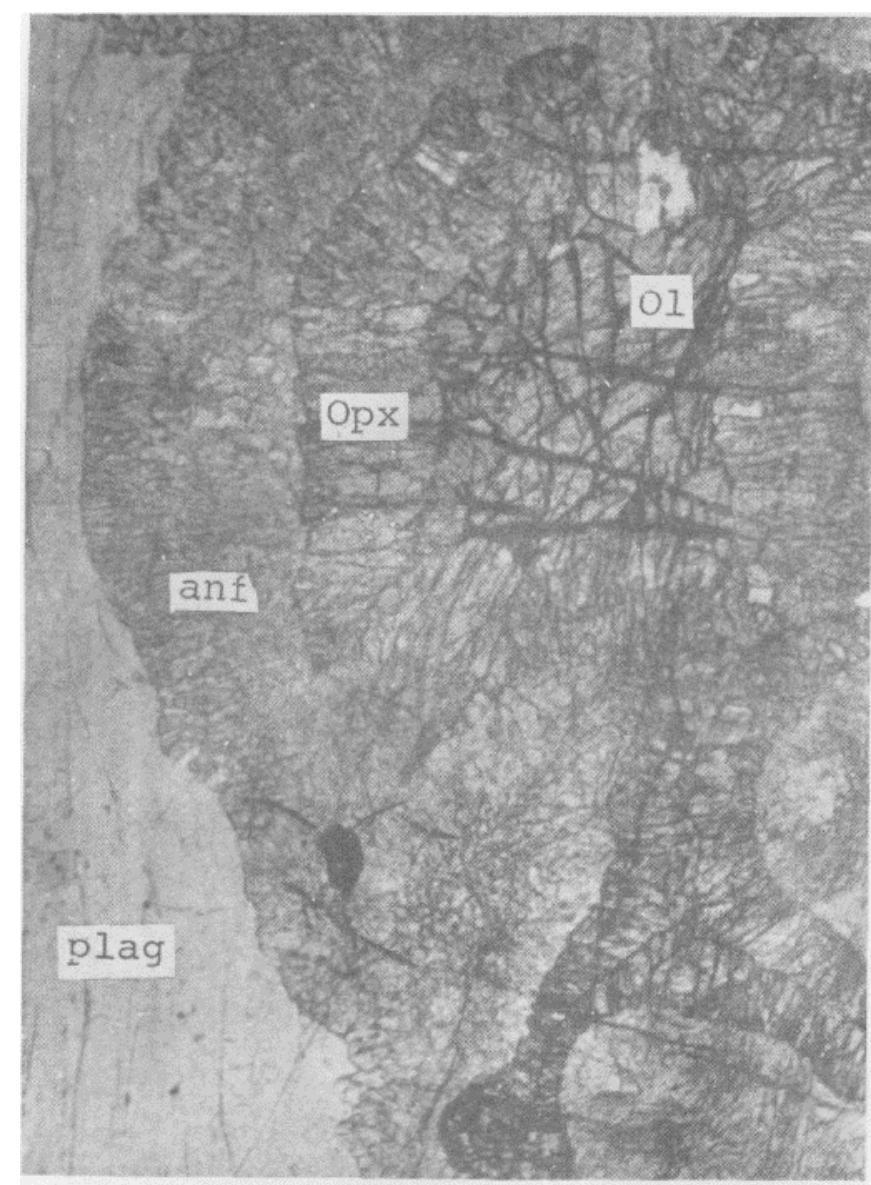

Fotomierografia 1 - Detalhe da corona em metaolivina gabronorito coronítico - resto de olivina (01), no núcleo; camada de ortopiroxênio prismático (Opx) bordejando com olivina e faixa de anfibólio (anf), com espinélio simplectítico próximo ao plagioclásio, Polarizadores descruzados, aumento $39 x$

Photomicrograph 1 - Detail of coronitic texture in meta olivine gabbronorite. Traces of olivine (ol) in the core, rim of prismatic orthopyroxene bordered by amphibole and spinel in symplectitic intergrowth. Magnification $39 \mathrm{x}$. Nicols out

de 0,5 a $1,5 \%$ em peso nos ortopiroxênios de coronitos máficos, e de 1,0 a $2,0 \%$ em peso nos coronitos ultramáficos. $O$ $\mathrm{CaO}$ varia geralmente em tomo de $0,2 \%$ e o $\mathrm{MnO}$ entre 0,2 a $0,3 \%$ em peso.

Os ortopiroxênios coroníticos são textural e quimicamente distintos dos ortopiroxênios magmáticos, intercumulus, eventualmente presentes na rocha.

Nos meta-peridotitos/harzburgitos com clorita, há uma reorganização textural e mineralógica global da rocha, e os ortopiroxênios, tanto os coroníticos como os intercumulus, são recristalizados, passando a apresentar texturas granoblástícas. Quimicamente, mostram relação $\mathrm{Fe} / \mathrm{Mg}$ em equilíbrio com a olivina (Fig. 1), baixo teor em $\mathrm{Al}_{2} \mathrm{O}_{3}$ (de 1 a $2 \% \mathrm{em}$ peso) e baixo $\mathrm{CaO}(0,2$ a $0,3 \%$ em peso $)$.

Anfibólios Várias análises foram realizadas visando a caracterização da composição química dos anfibólios presentes nas diferentes associações. Para a avaliação das variações composicionais dos anfibólios na corona, foram efetuadas várias secções transversais a esta. Apesar das dificuldades analíticas, foram observadas variações sistemáticas adiante comentadas.

A fórmula estrutural dos anfibólios foi calculada com base em 23 átomos de oxigênio (base anidra), admitindo-se $\mathrm{FeO}=$

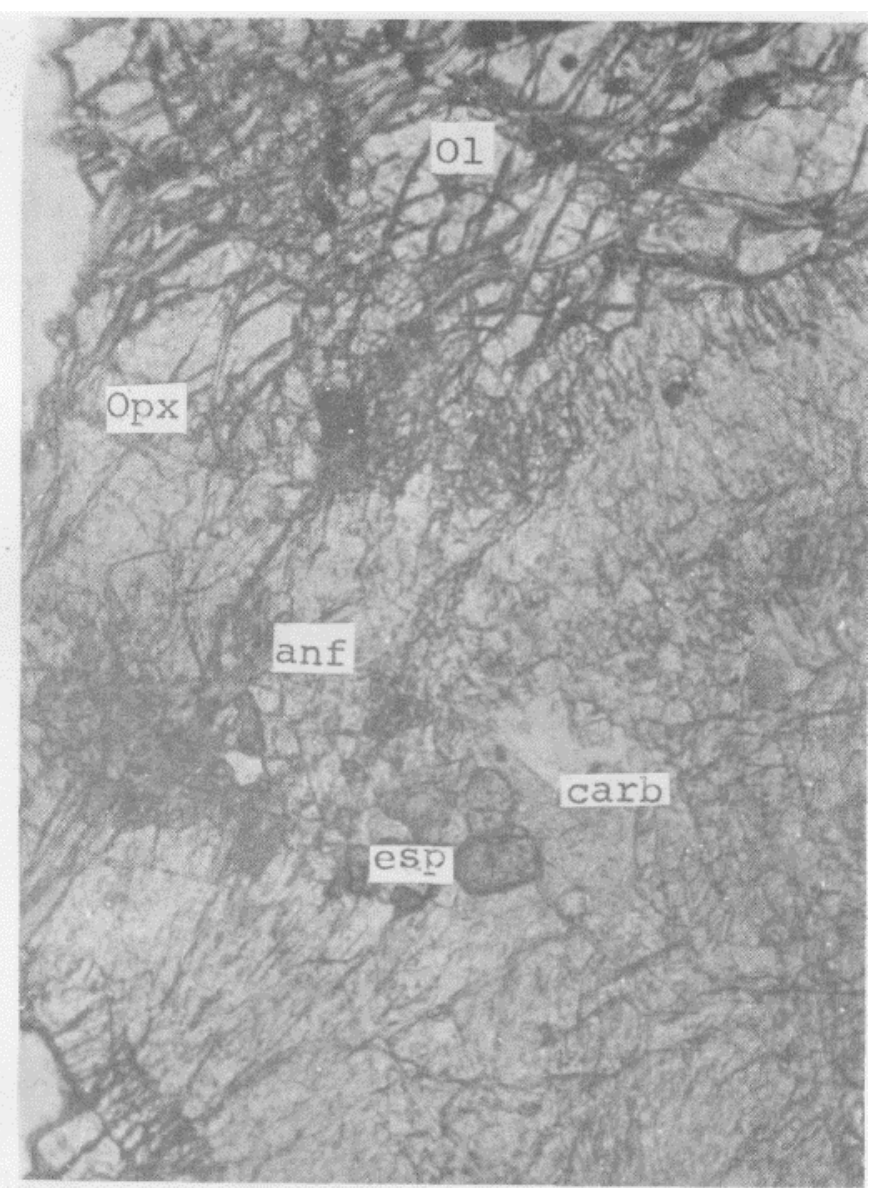

Fotomicrografia 2 - Metaperidotito com espinélio - detalhe Cristal de olivina (01) bordejado por ortopiroxênio (Opx) granular, imerso em agregado granular de anfibólio (anf) e espinélio (esp). Alguns cristais de carbonato (carb) (dolomita) próximo ao espinélio. Polarizadores descruzados, aumento $50 x$

Photomicrograph 2 - Metaperidotite with spinel. Olivine (oi) bordered by orthopyroxene (opx) and surrounded by granular amphibole (anf) and spinel (esp). Some grains of carbonate, dolomite, (carb) next to spinel. Nicols out, magnification $50 \mathrm{x}$

$\mathrm{Fe}_{\text {total }}$. A expressão de $\mathrm{Fe}_{\text {total }}$ como $\mathrm{FeO}$ fornece valores mínimos de $\mathrm{Al}^{\mathrm{IV}}$ e máxima ocupação de (A) (Robinson et al 1971). Entretanto, tratando-se de rochas essencialmente magnesianas, os desvios causados pela presença de $\mathrm{Fe}^{3+}$, embora presentes, devem estar minimizados. Os resultados analíticos encontram-se representados nos diagramas das figuras 2 e 3 para anfibólios de litotipos ultramáficos e máficos, respectivamente, adaptados à classificação de Leake (1978).

Os diagramas mostram que os anfibólios presentes nas associações coroníticas e com espinélio, tanto nos litotipos ultramáficos como nos máficos, apresentam composições no campo da pargasita e hornblenda pargasítica (campo delimitado por linhas tracejadas, Figs. 2 e 3 ), nos quais o $\mathrm{Al}^{\mathrm{IV}}$ varia de 1,6 a 2,0 (até 2,2 em alguns casos) cations por fórmula estrutural, valores comumente apresentados por anfibólios de rochas ultramáficas de alto grau (Evans 1982). Os demais pontos composicionais representados correspondem a anfibólios de meta-peridotitos/harzburgitos com clorita (Fig. 2) e de meta-olivina gabros (Fig. 3), e se distribuem tendendo ao pólo da tremolita. Em seu conjunto, os anfibólios mostram variação composicional marcada pelo decréscimo simultâneo de $(\mathrm{Na}$ $+\mathrm{K})_{\mathrm{A}}$ e $\mathrm{Al}^{\mathrm{IV}}$ em ambos os tipos litológicos. Em sua maioria, os pontos situam-se entre as retas que indicam relação $(\mathrm{Na}+\mathrm{K})_{\mathrm{A}}: \mathrm{Al}^{\mathrm{IV}}$ entre 1:2 e 1:3, campo de variação composi- 


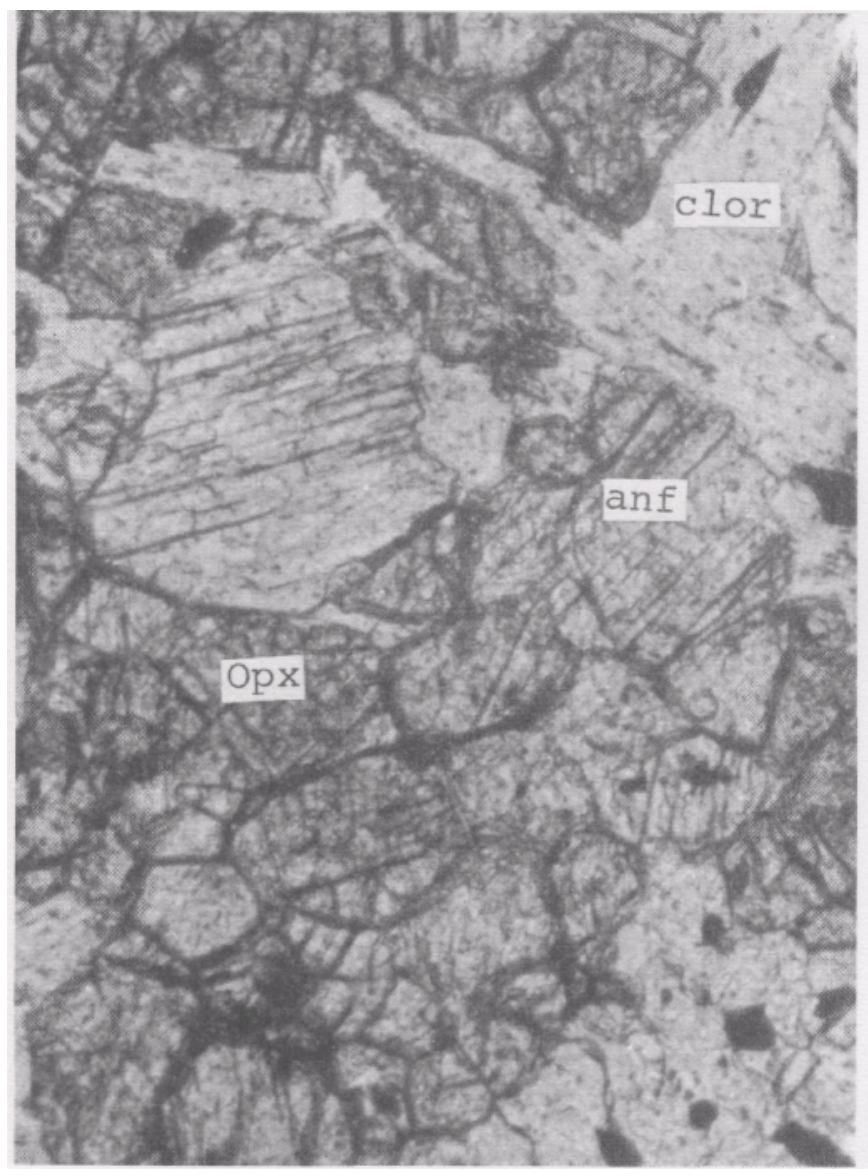

Fotomicrografia 3 - Metaperidotito com clorita - associação de ortopiroxênio (Opx) (relevo alto) - anfibólio (anf) (relevo médio) e clorita (clor) (relevo baixo) com textura granoblástica. Polarizadores descruzados, aumento $156 x$ Photomicrograph 3 - Metaperidotite with chlorite. Orthopyroxene (opx), amphibole (anf) and chlorite (clor) showing granoblastíc texture. Nicols out, magnification $156 \mathrm{x}$

cional determinado por Robinson et al. (1971, 1982) para anfibólios cálcicos, sendo que tal relação indica que nos anfibólios deve ocorrer um maior número de substituições tschermakíticas que as necessárias para a formação da pargasita. A projeção de $\mathrm{Al}^{\mathrm{IV}}-\mathrm{A} 1^{\mathrm{VI}}$ (Fig. 4) mostra que $\mathrm{A} 1^{\mathrm{VI}}$ atinge proporções máximas da ordem de $1,4 \mathrm{~A} 1^{\mathrm{VI}}: 2 \mathrm{Al}^{\mathrm{IV}}$, o que também concorda com os valores comumente encontrados em anfibólios cálcicos desta natureza (Robinson et al. 1971). O conteúdo atômico de $\mathrm{Ca}$ em $\mathrm{M}(4)$ é relativamente constante, com valores médios em torno de 1,6 a 1,7 cations por fórmula estrutural. A ocupação de Fe e/ou Mg em M(4) (componente cummingtonítico) alcança valores de 16 a $17 \%$, enquanto $\mathrm{Na}$ em $\mathrm{M}(4)$ varia de $\mathrm{O}$ a 0,15 , conteúdo compatível em anfibólios com grande quantidade de substituições tschermakíticas e edeníticas (Evans 1982).

Variações composicionais dos anfibólios nas coronas Nas associações coroníticas, os anfibólios mostram nítida variação composicional ao longo da corona, marcada principalmente pela variação de $\mathrm{Al}_{2} \mathrm{O}_{3}$ e $\mathrm{MgO}$. Do ortopiroxênio em direção ao plagioclásio, o anfibólio mostra aumento em $\mathrm{Al}_{2} \mathrm{O}_{3}$ e concomitante diminuição em $\mathrm{MgO}$, observando-se valores máximos em $\mathrm{Al}_{2} \mathrm{O}_{3}$ (e mínimos em $\mathrm{MgO}$ ) nos anfibólios mais próximos ao plagioclásio.

Nas associações com espinélio, entretanto, os anfibólios voltam a apresentar teores relativamente diminuídos em $\mathrm{Al}_{2} \mathrm{O}_{3}$

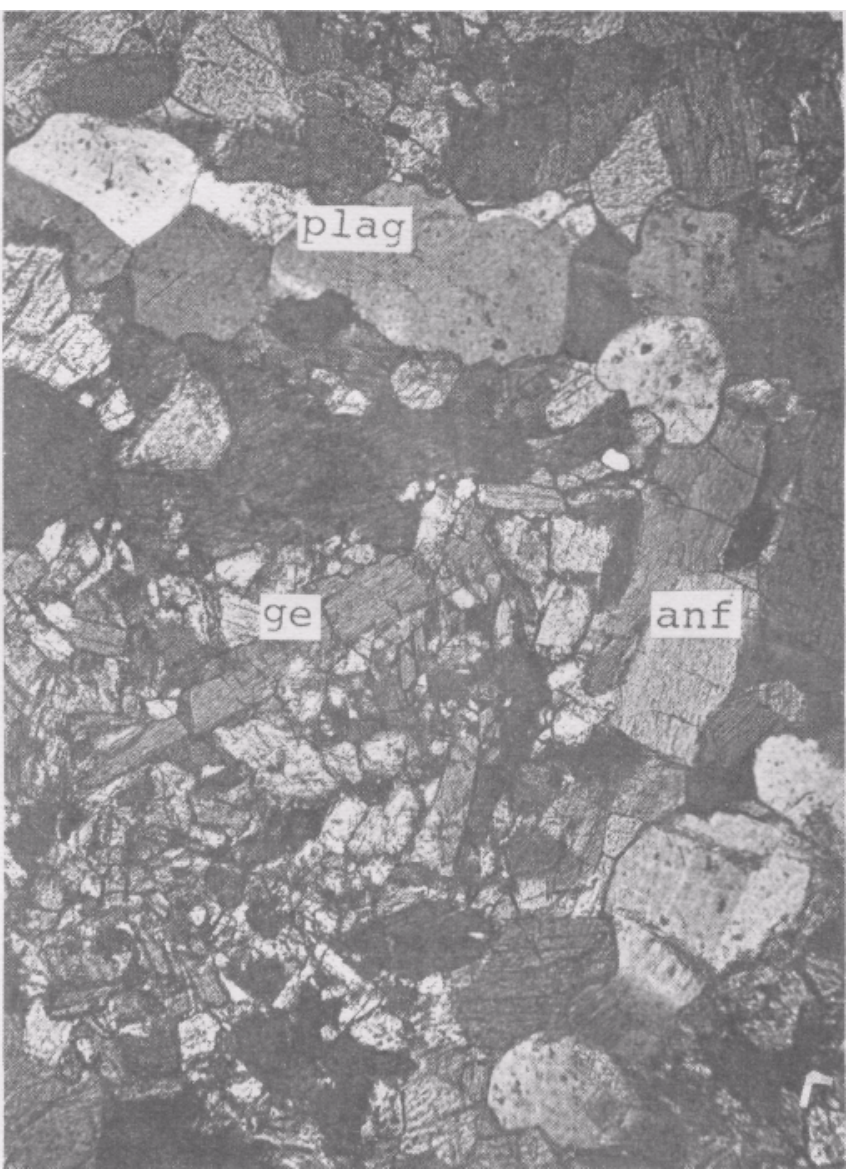

Fotomicrografia 4 - Metaolivina gabronorito ré cristalizado, mostrando a associação plagioclásio (plag) (andesina), magnésio-hornblenda (anf), ortoanfibólio (gedrita-ge) com texturas granoblásticas. Polarizadores parcialmente cruzados, aumento 50,4 $x$

Photomicrograph 4 - Recrystallised meta olivinegabbronorite. Granoblastíc texture of plagioclase (plag), amphibole (anf) and ortho amphibole (gedrite) (ge). Magnification $50 \mathrm{x}$. Nicols partially out

Tabela 1 - Associações e fases minerais de interesse neste trabalho

Table 1 - Parageneses and mineral phases of interest in this work

\begin{tabular}{|c|c|c|c|}
\hline ASSOCIAÇŌES & (a) CORONITICOS & (b) À ESPINÉLIO & (c) À CLORITA \\
\hline Meta-peridotito & o & a & Ol \\
\hline /harzburgito & Opx $x_{c}$ & Opx & Opx \\
\hline (litologias & $($ Anf + Esp) & Anf & Anf (magnésio-homblenda) \\
\hline \multirow[t]{2}{*}{ ultramáficas) } & Plag & Esp \pm Carb & Clor (clinocloro) \\
\hline & (d) CORONITICOS & (e) À ESPINÉLIO & (f) META GABROS \\
\hline Meta-olivina & $a$ & Opx & Plag \\
\hline gabronoritos & Opx $x_{c}$ & Anf & Anf (magnésio-homblenda) \\
\hline (litologias & $($ Anf + Esp) & Esp & Ortoanf (gedrita) \\
\hline máficas) & Plag & $\begin{array}{l}\text { Plag } \\
\pm \text { Carb }\end{array}$ & \\
\hline
\end{tabular}

Abreviações: Ol - divina; Opx - ortopiroxênio; Plag - plagioclásio; Anf - anfibólio cálcico; Esp - espinélio; Clor - clorita; Carb - carbonato; Ortoanf - ortoanfibólio. Subscritos: c coronítíco; s - simplectitico. Associações (a), (b), (d) e (e) - com estruturação coronítíca; (c) e (f) - granoblásticas

e mais elevados em $\mathrm{MgO}$, indicando que, com a individualização do espinélio (fase enriquecida em $\mathrm{Al}$ e $\mathrm{Fe}$ ) há uma modificação na composição do anfibólio, que se torna mais pargasítico e mais magnesiano. 


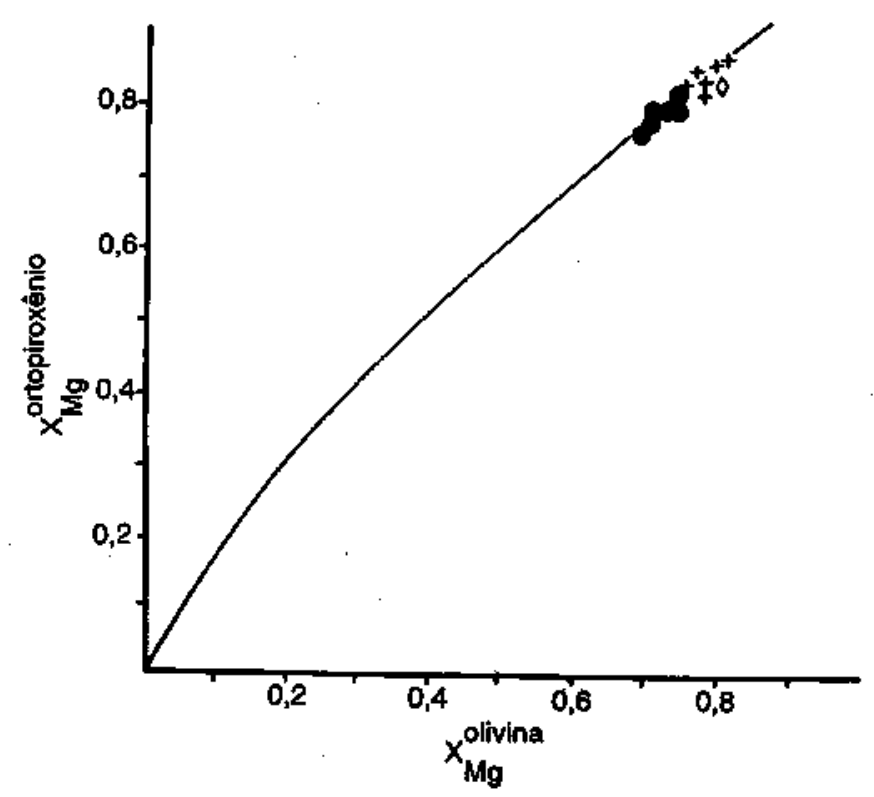

Figura l-Partição de Fe e Mg entre olivinas e ortopiroxênios em coronitos ultramáficos (+), coronitos máficos $(\bullet)$ metaperidotitos com clprita (0)

Figure $1-\mathrm{Fe} / \mathrm{Mg}$ distribution between olivine and opx in coronas from ultramafic $(+)$, mafíc $(\bullet)$ and metaperidotitic rocks $(0)$
Tais variações são mostradas na figura 5 , em função da variação de $\mathrm{Al}^{\mathrm{VI}}$ e de $\mathrm{Mg}$ e $\mathrm{Fe}^{2+}$ (em número de cations por fórmula estrutural) na qual se nota que o aumento de $\mathrm{A}^{\mathrm{VI}}$ ocorre com concomitante decréscimo de $\mathrm{Mg}$, enquanto $\mathrm{Fe}$ (e demais cations, não representados) mantém suas porcentagens praticamente constantes. As variações podem ser, assim, relacionadas a um maior ou menor número de substituições tschermakíticas do tipo $\mathrm{MgSi}=\mathrm{Al}^{\mathrm{VI}} \mathrm{Al}^{\mathrm{VI}}$ no anfibólio ao longo da corona.

A substituição preferencial de $\mathrm{Mg}$ por $\mathrm{Al}$ reflete-se diretamente no valor da relação $\mathrm{Fe} / \mathrm{Mg}$. Se por um lado tal razão é certamente função da razão $\mathrm{Fe} / \mathrm{Mg}$ da olivina (e do ortopiroxênio em equilíbrio), por outro lado é também função do grau de substituições tschermakíticas no anfibólio. $\mathrm{Na}$ figura 6 , está representada a variação da relação $\mathrm{Fe} / \mathrm{Mg} \mathrm{em}$ olivinas, ortopiroxênios e anfibólios coroníticos relacionados e, para comparação, foi também representada a curva de $\mathrm{Kd}=1$ citada por Evans (1982) por anfibólios pargasíticos com $\mathrm{Al}^{\mathrm{IV}}$ próximo a 1,8 .

Ortoanfibólios A presença de ortoanfibólio é observada nos meta-olivina gabronoritos recristalizados, em associacão com plagioclásio e magnésio-homblenda. O ortoanfibólio mostra composições no campo da gedrita com $\mathrm{Al}^{\mathrm{IV}}$ de 1,4 a 1,8 e razão $\mathrm{Mg} / \mathrm{Mg}+\mathrm{Fe}$ da ordem de 0,7 a 0,8 .

Espinélios Os espinélios coroníticos apresentam composições essencialmente aluminosas, com razões $\mathrm{Al} / \mathrm{Al}+\mathrm{Cr}$ $+\mathrm{Fe}^{3+}$ da ordem de 0,96 a 0,$98 ; \mathrm{Fe}^{3+} / \mathrm{Fe}^{3+}+\mathrm{Al}+\mathrm{Cr}$ entre 0,01 e 0,02 e $\mathrm{Cr} / \mathrm{Cr}+\mathrm{Fe}^{3+}+\mathrm{Al}$ de 0,01 a 0,02 . Apesar do limitado número de análises, é possível definir-se um Kd da ordem de 2,5 para a partição de Fe e $\mathrm{Mg}$ entre olivina e espinélio (Fig. 7). Tal valor é pouco superior ao determinado por Frost (1975) para a partição de Fe e Mg entre espinélio

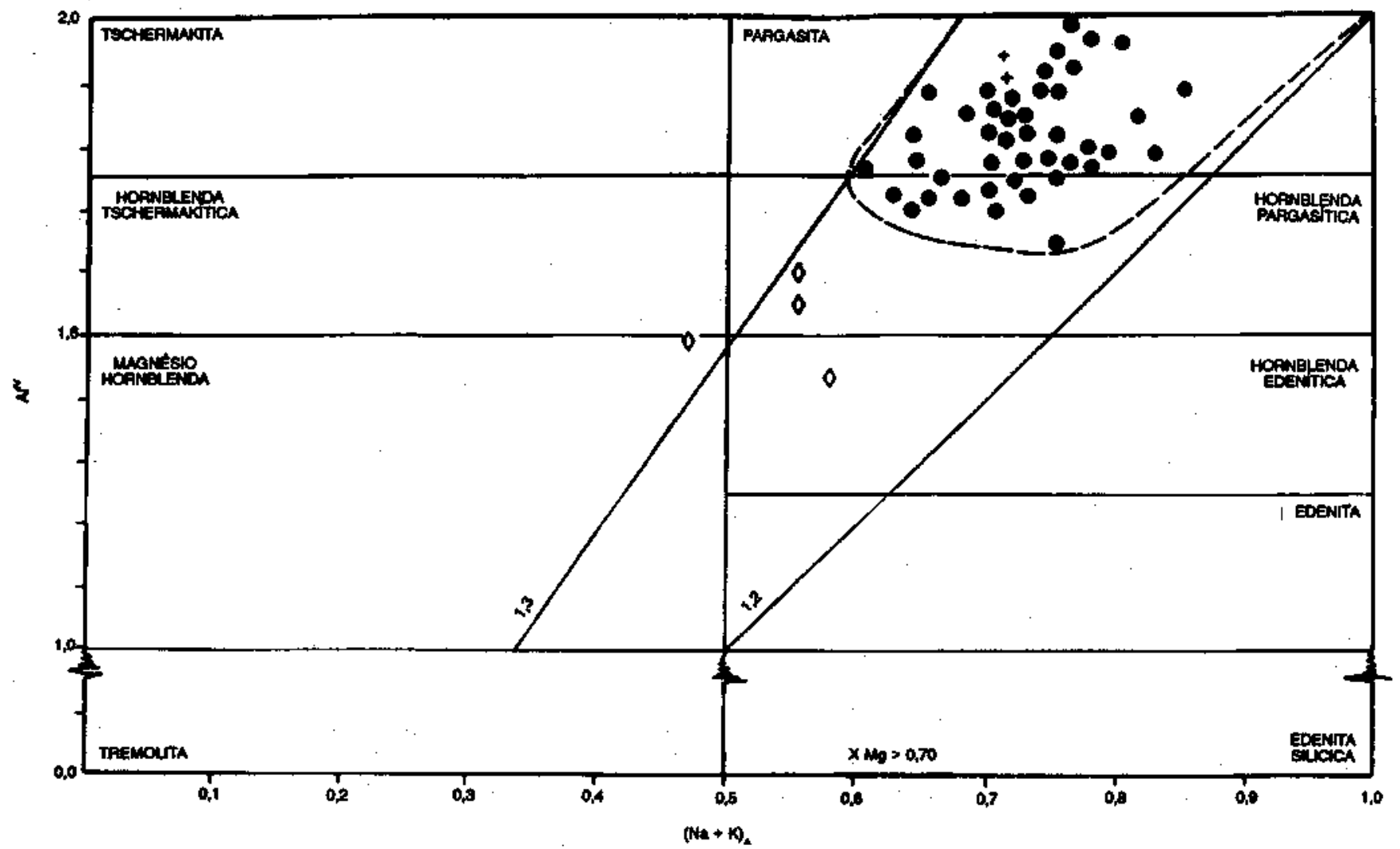

Figura 2 - Variação compositional dos anfibólios cálcicos nas litologias ultramáficas dos Complexos de Mangabal I e II. Associações coroníticas (•), com espinélio (+) e com clorita $(\diamond)$

Figure 2 - Chemical composition of the calcic amphiboles in ultramafic rocks of Mangabal I e IL Coronitic $(\bullet)$, spinel-bearing $(+)$ and chlorite-bearing rocks $(\diamond)$ 


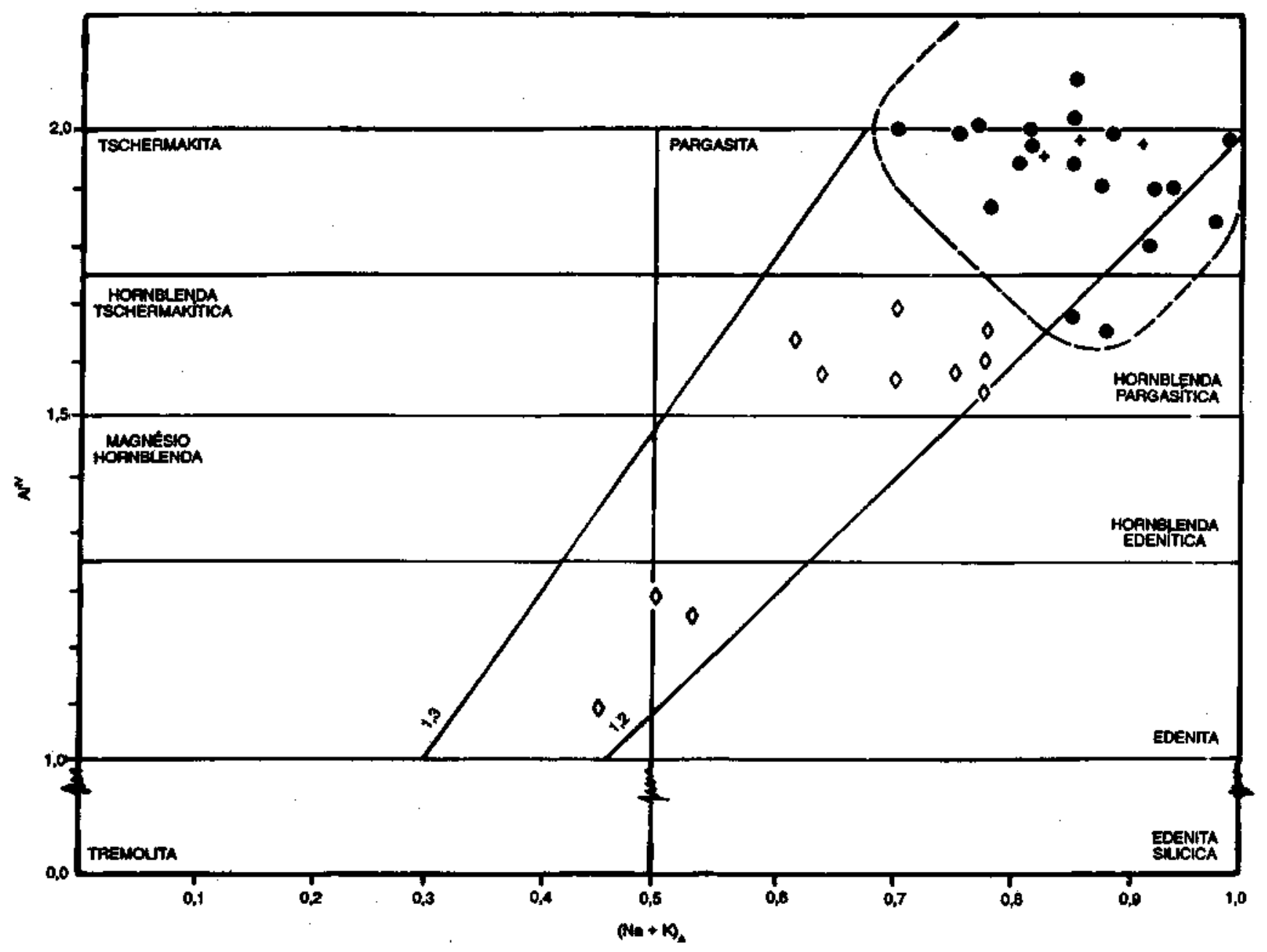

Figura 3 - Variação compositional dos anfibólios cálcicos em litologias máficas dos Complexos Mangabal I e II. Associações coroníticas $(\bullet)$, com espinélio $(+)$ e em olivina gabronorito $(\diamond)$

Figure 3 - Chemical composition of the calcic amphibole in mafic rocks of Mangabal I and II, coronitic $(\bullet)$, spinel-bearing $(+)$ and olivine gabbronorite $(\diamond)$

e olivina $(\mathrm{Kd}=2,0)$ na associação olivina - clorita - enstatita - espinélio.

Plagioclásios Nos coronitos ultramáficos, o plagioclásio original, intercumulus, tem composição em torno de $\mathrm{An}_{63-64}$, sendo a fase consumida com o desenvolvimento das coronas.

Nos olivina gabronoritos coroníticos, o plagioclásio ocorre como fase cumulus. Sua composição original apresenta teores em tomo de $\mathrm{An}_{64}$, mostrando zoneamento normal onde alcança teores em torno de $\mathrm{An}_{52-53}$. Os plagioclásios reliquiares apresentam-se geralmente turvos, principalmente na parte central. Com o desenvolvimento das coronas, o plagioclásio próximo às coronas mostra-se recristalizado (granoblástico e sem turvamente) e com composições no campo da labradorita $\left(\mathrm{An}_{53}\right.$, geralmente). Face ao zoneamento, é difícil estabelecer quais as variações químicas que ocorrem com a formação das coronas (se se toma mais cálcico ou mais sódico, dependendo da fase reagente ser núcleo ou borda), entretanto, todos os plagioclásios analisados têm composições labradoríticas.

Nos meta-olivina gabronoritos recristalizados, o plagioclásio apresenta-se límpido, com texturas granoblásticas e composições no campo da andesina.

Cloritas Composicionalmente, as cloritas participantes da associação de metaperidotitos/harzburgitos com clorita correspondem ao termo clinocloro (segundo classificação de
Hey 1954 in Deer et al 1977), com teor de $\mathrm{Al}^{\mathrm{IV}}$ entre 2,1 e 2,4 e composições essencialmente magnesianas.

REAÇÕES CORONÍTICAS Considerações gerais

São analisadas preliminarmente as evidências químico-petrográficas indicativas da suposta formação e desenvolvimento das coronas em sistema fechado, bem como as evidências petrográf icas relativas à mobilidade dos elementos e natureza da fase fluida. Tais evidências sustentam o equacionamento termodinâmico desenvolvido para as reações coroníticas estudadas.

O caráter isoqiumico ou aloquímico das reações coroníticas é assunto bastante controvertido; vários modelos foram elaborados por diversos autores. Grieve \& Gittins (1975) revisam as várias hipóteses em coronitos semelhantes, ressaltando a possibilidade da atual interface ortopiroxênio-anfibólio não corresponder necessariamente à interface olivina-plagioclásio original (o que é provável que ocorra, embora não se tenham evidências diretas), como também admitem a possibilidade da olivina modificar sua composição com a formação de coronas (o que não parece ser o caso nas coronas analisadas neste trabalho, pois as olivinas, coroníticas ou não, apresentam composição essencialmente constante na amostra). Lamoen (1979) admite sistema aloquímico a partir de balanceamento de massa de reações coroníticas similares, envolvendo fases minerais de composição química constante na corona. No caso das coronas analisadas, os dados químicos mostram que, 


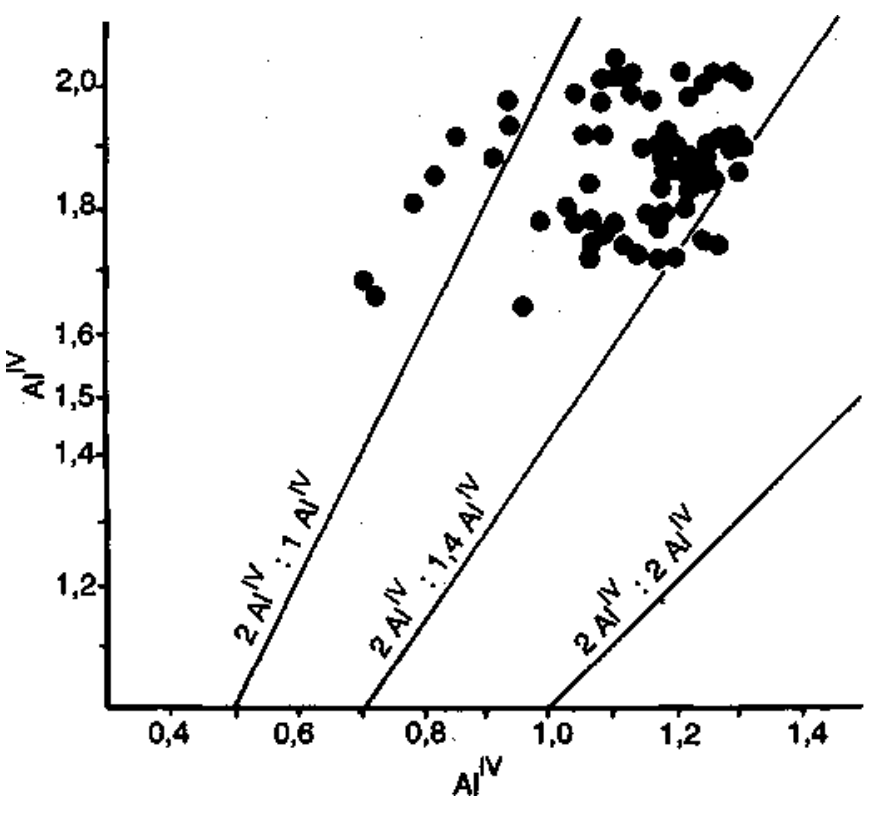

Figura 4 - Variação da relação $A I^{V I} \times A I^{I V}$ nos anfibólios cálcicos de litologias ultramáficas e máfitas dos Complexos de Mangabal I e II

Figure 4 - Octahedral versus tetrahedral Al of calcic amphiboles of Mangabal I and II (cation number of formula unit)

enquanto olivina e ortopiroxênio tem composições relacionadas e constantes na corona, o anfibólio apresenta variações químicas notáveis, o que impede equacionamentos rígidos de balanceamento atômico.

A viabilidade das reações coroníticas evoluírem em sistemas fechados é admitida e avaliada teoricamente por Nishiy ama (1983) em coronitos com estruturação semelhante aos estudados.

Embora sejam parâmetros de difícil quantificação, as evidências petrográf icas e químicas das coronas estudadas neste trabalho apontam para sistema fechado, como analisado a seguir.

Um primeiro ponto é que as coronas desenvolvem-se sempre que e somente quando olivina e plagioclásio encontram-se em contato, independente da presença e natureza das demais fases minerais presentes na rocha. Isto indica que as reações ocorrem num subsistema formado por estes dois minerais, o qual contém os componentes reagentes necessários (com excessão da fase fluida) para a reação, sem haver necessidade de aporte/retirada de componentes externos ao sistema.

Com base nos dados de quimismo mineral, é verificado primeiro que, a relação $(\mathrm{Na}+\mathrm{K}) / \mathrm{Ca}$ nos anfibólios analisados é aproximadamente 1:2, sendo semelhante à do plagioclásio presente, seja nos olivina gabronoritos seja nos peridotitos/harzburgitos feldspáticos, admitindo-se composições médias em torno de $\mathrm{An}_{62-63}$ para os plagioclásios.

Em segundo lugar, comparando a relação $\mathrm{Fe} / \mathrm{Mg}$, nota-se haver redistribuição destes elementos nas fases produzidas pela reação coronítica, de forma a manter coerência entre esta relação na olivina e nas fases coroníticas em conjunto. De fato, enquanto ortopiroxénio (e anfibólios, embora de forma mais variável) representa fase com pequeno enriquecimento em magnésio, o espinélio é fase nitidamente enriquecida em ferro. Por estas evidências, não haveria necessidade de introduzir (ou remover) $\mathrm{Fe}$ ou $\mathrm{Mg}$ no sistema para a evolução das coronas (Lamoen 1979).

As análises químicas de rocha total de coronitos e equivalentes recristalizados também indicam a hipótese de sistema fechado. No conjunto analisado, comparando-se amostras em diferentes graus de coronitização, não se observa nenhuma variação química particular em função do "grau de coronitização", o que seria esperado se a evolução da corona fosse vinculada à introdução ou remoção de elementos específicos no sistema.

Face ao conjunto de evidências, admite-se que as reações coroníticas processam-se em sistema essencialmente fechado (isoquímico), isto é, o sistema permanece aberto somente à introdução de fluidos.

No que concerne à mobilidade dos elementos, a evolução das coronas nos olivina gabronoritos é particularmente elucidativa para a interpretação das transformações que devem ocorrer na formação das coronas. Nessas rochas, confrontando-se coronas em diferentes estágios de evolução, nota-se que a reação leva gradativamente à eliminação da olivina, culminando com sua total substituição por ortopiroxénio. Tal fato indica que deve haver liberação de sflica durante a reação coronítica e que a sílica então liberada deve difundir-se através da corona e alcançar o núcleo de olivina, onde é consumida na formação de ortopiroxênio. Neste processo, a olivina funcionaria como tampão para sflica, cuja difusão deve ser facilitada pela estrutura fibro-radiada da corona. Liberação de silica é também admitida por Lamoen (1979) na formação de coronitos semelhantes.

O alumínio tende a concentrar-se nas partes mais externas da corona, fato evidenciado pela abundância de espinélio alutninoso na interface anfibólio-plagioclásio. Magnésio e ferro difundem-se da olivina para o plagioclásio, fixando-se preferencialmente no anfibólio e espinélio neoformados, respectivamente (concordando com Mongkoltip \& Ashworth 1983).

A formação das coronas é certamente ligada à introdução de $\mathrm{H}_{2} \mathrm{O}$ no sistema, fase fluida fixada na formação do anfibólio coronítico. O desenvolvimento diferencial das coronas pode ser explicado pelo esgotamento de uma fase reagente. No caso das coronas estudadas, a interrupção do processo é devida ao esgotamento de $\mathrm{H}_{2} \mathrm{O}$ na fase fluida, visto que as demais fases reagentes ainda estão presentes. A presença de carbonato nas associações contendo espinélio, bem como a natureza das inclusões fluidas, indicam a participação de $\mathrm{CO}_{2}$ na fase fluida; porém, este componente não intervém diretamente nas reações coroníticas. Estes aspectos serão retomados adiante.

As reações coroníticas são assim modeladas, admitindo-se que as coronas se desenvolvem pela difusão de elementos em sistema fechado, em presença de fase fluida constituída por $\mathrm{H}_{2} \mathrm{O}$ e $\mathrm{CO}_{2}$, sendo $\mathrm{H}_{2} \mathrm{O}$ o fluido participante da reação.

Estequiometria das reações e cálculos termodinâmicos As coronas podem ter sua formação explicada pela atuação conjunta de duas reações acopladas:

$(2 \mathrm{An}+1 \mathrm{Ab})+2,5 \mathrm{OI}+\mathrm{H}_{2} \mathrm{O}=1 \mathrm{Parg}+1 \mathrm{Esp}+3,5 \mathrm{SiOi}(1)$

3,5 $\mathrm{SiO} 2+3,5 \mathrm{OI}-7 \mathrm{Opx}$

Abreviações: $\mathrm{An}=$ Anortita; $\mathrm{Ab}=$ albita (a proporção 2An: $1 \mathrm{Ab}$ é utilizada de forma a recompor $\left.\mathrm{An}_{63}\right) ; \mathrm{Ol}=$ olivina; Opx = ortopiroxênio; Parg = pargasita ideal (na reação é admitida a fórmula da pargasita ideal, pois, em associações contendo espinélio, o anfibólio volta a ter composições próximas à pargasita); Esp = espinélio.

A reação (1) leva à formação de pargasita e espinélio, com liberação de sflica, a qual é concomitantemente consumida na reação (2), com a formação de opx (tais reações concordam com o observado na evolução das caronas, onde olivina é transformada em opx).

A reação total da corona é representada pela equação:

$(2 \mathrm{An}+1 \mathrm{Ab})+6 \mathrm{O}+\mathrm{H}_{2} \mathrm{O}-7 . \mathrm{Opx}+1 \mathrm{Parg}+1 \mathrm{Esp}$ 

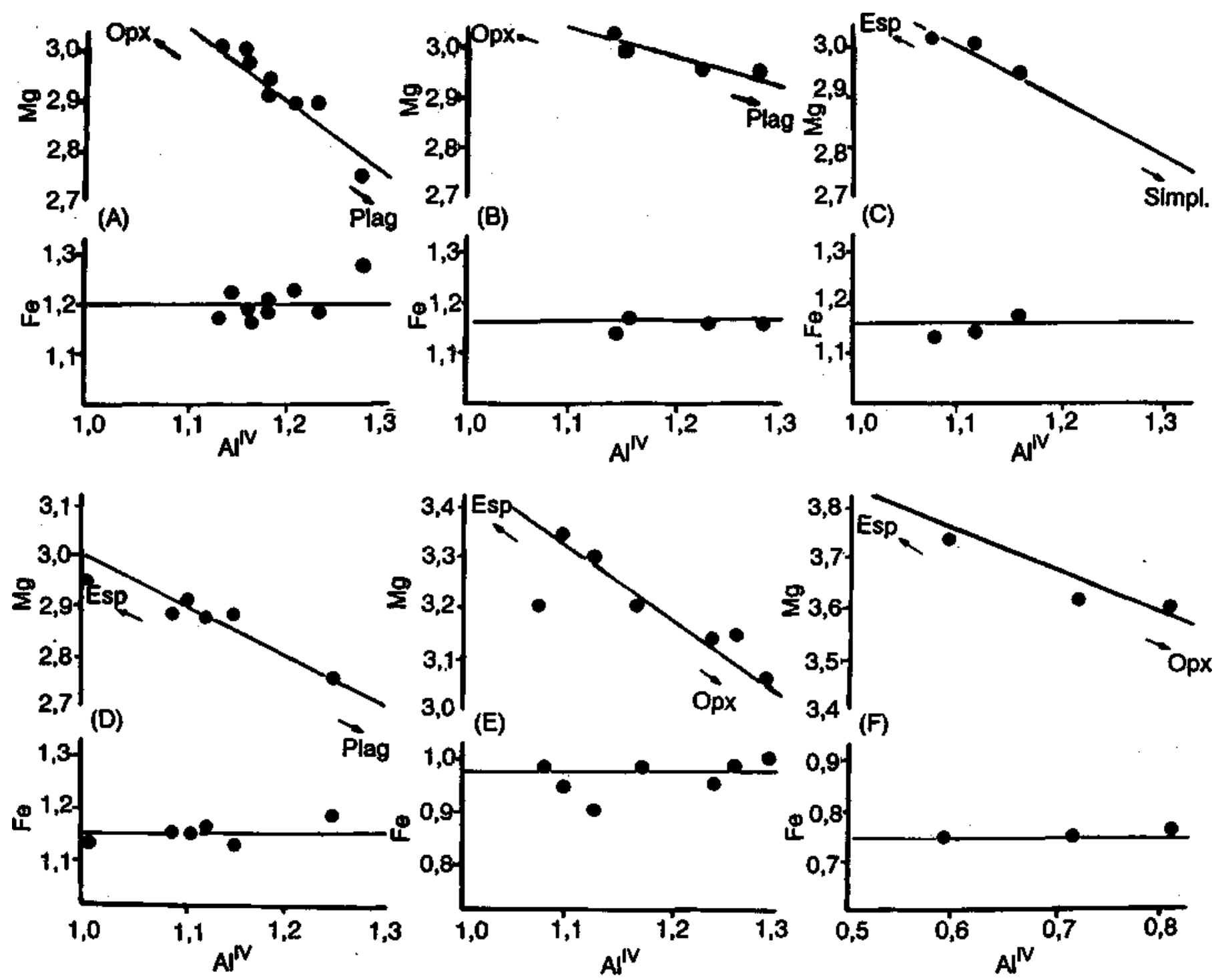

Figura 5 - Variação de Fe e Mg em função de Al $l^{V I}$ em anfibólios cálcicos (expressa em número de cations na fórmula estrutural) Figure 5 - Fe and $\mathrm{Mg}$ as function of tetrahedial Al in calcic amphiboles of Mangabal I and II

Admitindo-se fases de composição magnesiana, temos:

$$
\begin{aligned}
& \left(2 \mathrm{CaAl}_{2} \mathrm{SiO}_{2} \mathrm{O}_{8}+1 \mathrm{NaAlSi}_{3} \mathrm{O}_{8}\right)+\underset{\mathrm{V}=262}{\mathrm{MgSiO}_{4}}+\mathrm{H}_{2} \mathrm{O}= \\
& 7 \mathrm{MgSiO}_{3}+1 \mathrm{NaCa}_{2} \mathrm{Mg}_{4} \mathrm{Al}\left(\mathrm{Al}_{2} \mathrm{Si}_{6}\right) \mathrm{O}_{22}(\mathrm{OH})_{2}+1 \mathrm{MgAl}_{2} \mathrm{O}_{4} \\
& \mathrm{~V}=222 \quad \mathrm{~V}=273 \quad \mathrm{~V}=39
\end{aligned}
$$

onde, numa primeira aproximação, verifica-se que a relação entre os volumes (V) das fases produzidas em (4) reproduz adequadamente a relação modal observada entre os minerais coroníticos, isto é, a porcentagem modal dos espinélios é significativamente menor que a do anfibólio, cuja proporção é pouco superior à do ortopiroxênio (dados de volume em $\mathrm{cm}^{3} / \mathrm{mol}$, extraídos de Robie et al 1978).

Nessas reações, o esgotamento de qualquer fase reagente interrompe o desenvolvimento das coronas. Nos litotipos ultramáficos, as coronas completam-se com o esgotamento do plagioclásio, e nos olivina gabronoritos, com o desaparecimento da olivina. $\mathrm{O}$ esgotamento de $\mathrm{H}_{2} \mathrm{O}$ interrompe a reação em qualquer estágio, independente da composição global da rocha, sendo a presença de $\mathrm{H}_{2} \mathrm{O}$ ligada a fatores externos.

Em função da composição química das fases minerais presentes nas coronas em estudo, o equacionamento termodinâ- mico será desenvolvido para a reação (5), admitindo-se igual partição do $\mathrm{Fe}$ e $\mathrm{Mg}$, aproximação adotada, visto não se conhecer o devido valor do coeficiente de partição desses elementos entre todas as fases ferromagnesianas.

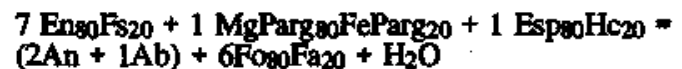

onde En = enstatita; Fs = ferrossilita $;$ MgParg = magnésiopargasita; FeParg = ferro-pargasita; Esp = espinélio; He = hercynita; $\mathrm{An}=$ anortita; $\mathrm{Ab}=$ albita; Fo - forsterita; $\mathrm{Fa}=$ faiaUta. A reação (5) foi invertida de forma a colocar as fases de maior temperatura como produtos.

Os valores das propriedades termodinâmicas para o plagioclásio de composição $\mathrm{An}_{66} \mathrm{Ab}_{33}$ foram calculados a partir dos dados tabelados em Helgeson et al (1978), levando-se em consideração a entalpia em excesso $\left(\Delta \mathrm{H}^{\mathrm{exc}}\right)$, por causa da solução sólida dos dois componentes puros, segundo Newton et al (1980).

Para forsterita, faialita, enstatita, ferrossilita e espinélio magnesiano, foram utilizados os valores de Helgeson et al (1978); para a hercmita, os valores de Robie et al (1978) e para a magnésio-pargasita, os de Westrich \& Holloway (1981). Para a ferro-pargasita, somente se encontram tabelados os 


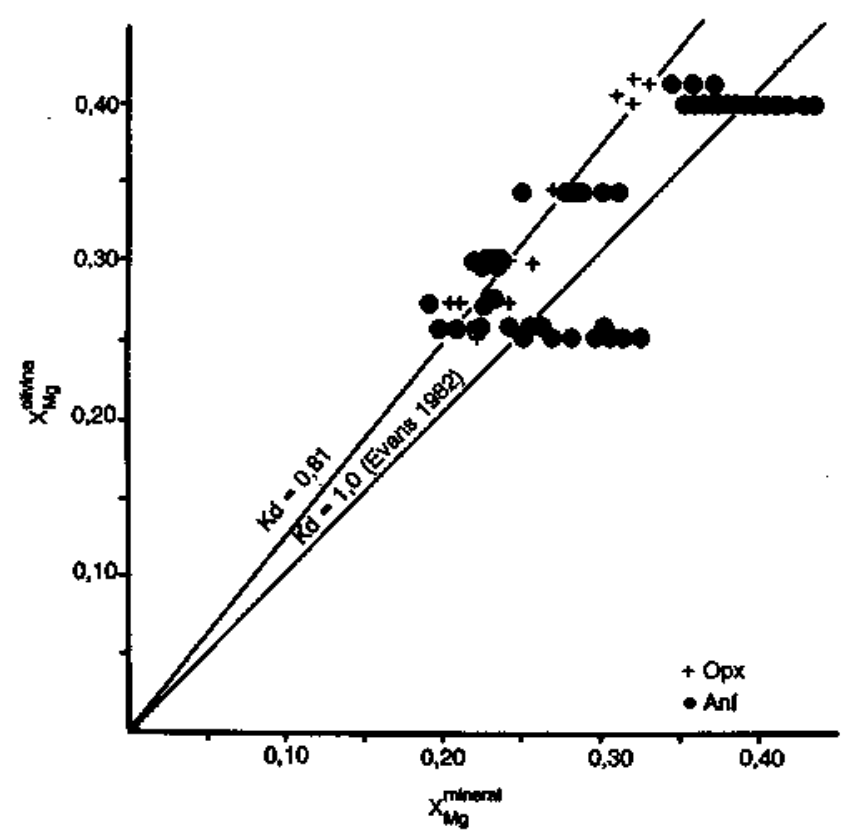

Figura 6 - Relação Fe/Mg em olivinas, ortopiroxênios e anfibólios coroníticos relacionados

Figure 6 - Fe/Mg relation of olivines, orthopyroxenes and amphiboles of coronitic minerais

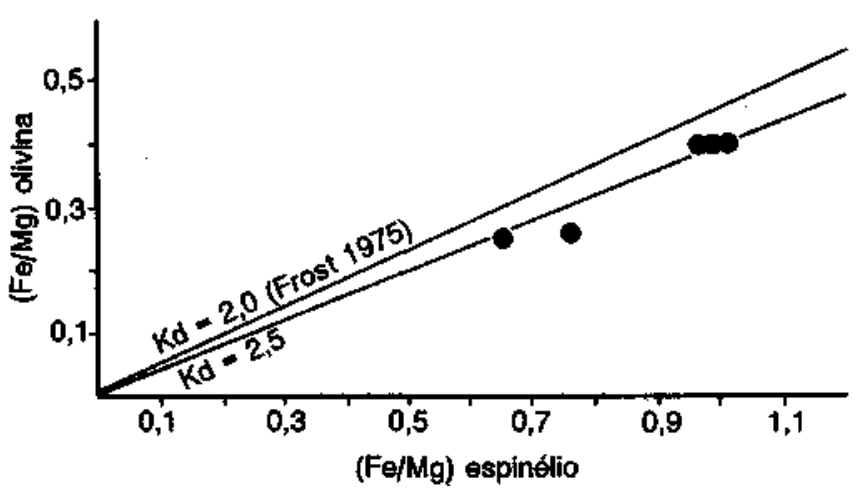

Figura 7 - Partição de Fe e Mg entre espinélio e olivina associada

Figure 7 - Distribution of $\mathrm{Fe}$ and $\mathrm{Mg}$ between olivine and spinel

valores de $\mathrm{V}^{\circ}$ e $\mathrm{S}^{\circ}$ (Helgeson et al 1978). O valor de AS? foi calculado dos dados de $\mathrm{S}^{\circ} \mathrm{Fe}$-pargasita (Helgeson et al 1978) e de $\mathrm{S}^{\circ}$ dos elementos ( $\mathrm{Na}, \mathrm{Ca}, \mathrm{Fe}, \mathrm{Al}, \mathrm{Si}, 02$ e $\mathrm{H}_{2}$ ) de Robie et al (1978). A obtenção de AG? para a ferro-pargasita, baseou-se nos dados experimentais de e $_{\mathrm{e}}$ Gilbert (1966), aplicando-se as equações e os valores de $\mathrm{GH}, \mathrm{O}$ fornecidos por Rsher \& Zen (1971).

Para a fase fluida $\left(\mathrm{H}_{2} \mathrm{O}\right)$, foram utilizados os valores de AG? de Robie et al (1978), e os valores de YHP foram extraídos de Ryzhenko \& Volkov (1971).

No diagrama da figura 8 , encontra-se projetada a curva de equilíbrio representativa da reação (5), em função de $T$ e $P_{t}$, admitindo-se $\mathrm{P}_{\mathrm{t}}=P H \&$, obtida a partir dos dados termodinâmicos. Para fins comparativos, foram também calculadas e representadas neste diagrama as curvas de equilíbrio das reações coroníticas para fases magnesianas (4) e f ases terrosas (6). As equações das reações representadas no diagrama da figura 8 encontram-se listadas na tabela 2.

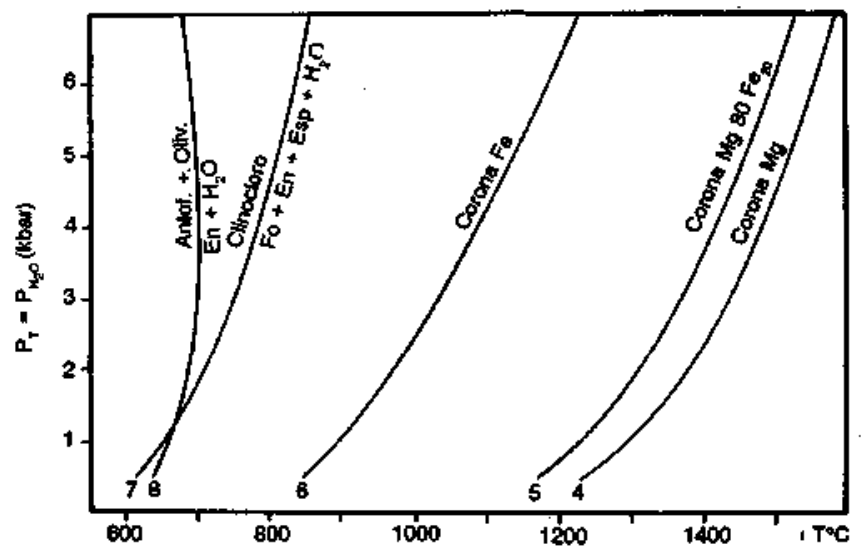

Figura 8 - Diagrama pressão-temperatura para as reações coroniticas (curvas 4, 5 e 6) e curvas representativas da quebra do clinocloro (7) e da enstatita (8)

Figure 8 - Calculated P-T conditions for coronitic reactions (4, 5 and 6$)$, upper limit of clinochlore (7) and enstatite (8)

Foram incluídas na figura 8 as curvas de equilíbrio das reações

1 antofilita +1 divina - 9 enstatita $+\mathrm{H}_{2} \mathrm{O}$

1 clinocloro $=1$ forsterita +2 enstatita +1 espinélio $+\mathrm{H}_{2}(8)$

que representam, respectivamente, as reações de desestabilização da enstatita e do clinocloro, fases presentes nas associações ultramáficas recristalizadas. As equações destas reações foram calculadas a partir dos dados de Helgeson et al (1978) e Robie et al (1978).

O diagrama da figura 8 mostra que a associação olivina-plagioclásio $\left(\mathrm{An}_{66}\right)$ tem seu campo de estabilidade limitado pelas curvas (4), para olivinas ricas em $\mathrm{Mg}$, e (6), para olivinas ricas em Fe; no caso das coronas em estudo, com composições intermediárias, pela curva (5). Tais reações ocorrem em temperaturas bastante elevadas, que, em particular no caso de olivinas com composições predominantemente magnesianas, excedem o campo dos processos metamórficos crustais. Nas transformações metamórficas, a associação olivina-plagioclásio torna-se instável em presença de $\mathrm{H}_{2} \mathrm{O}$, e essas fases tenderão a reagir quando da introdução de $\mathrm{H}_{2} \mathrm{O}$ no sistema. Tal reação se extenderá enquanto existir $\mathrm{H}_{2} \mathrm{O}$ e/ou até que uma das fases reagentes seja eliminada da associação.

Numa primeira interpretação (admitindo-se $\mathrm{P}_{\mathrm{T}}=\mathrm{P}_{\mathrm{H}_{2} \mathrm{O}}$ ), as coronas em estudo podem ter sido formadas a partir do momento em que houve introdução de $\mathrm{H}_{2} \mathrm{O}$ no sistema, desestabilizando a associação olivina-plagioclásio gerada por processos ígneos e, desenvolvendo, nas rochas ultramáficas, a associação mineralógica compatível com aquela estável entre as curvas (5) e (8). Estas marcam, respectivamente, as condições de desestabilização da associação olivina-plagioclásio e o limite inferior de estabilidade da associação espinélio-forsterita-enstatita - esta apresentada pelos peridotitos e harzburgjtos com espinélio. Nas rochas máficas (olivina gabronoritos), admite-se o mesmo limite para a desestabilização da associação clivina-plagioclásio (curva 5). Entretanto, não há dados que permitam mferir o limite inferior desta associação neste tipo litológico.

CONDICÕES DE METAMORFISMO DAS ROCHAS DOS COMPLEXOS O estabelecimento das condições de temperatura-pressão total e pressão de fluidos dos reequilíbrios minerais baseia-se na interpretação integrada das diferentes associações desenvolvidas no conjunto das rochas 


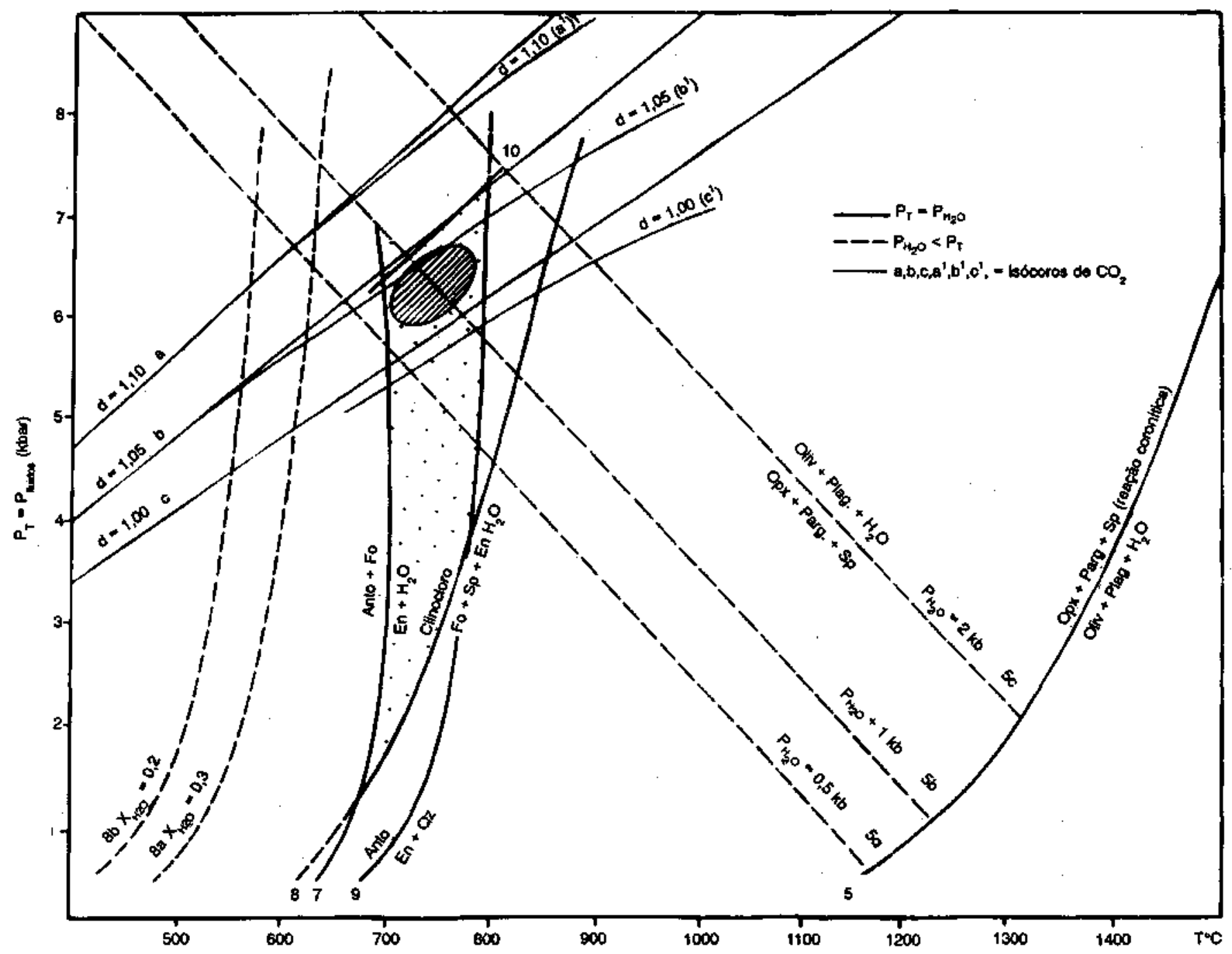

Figura 9 - Diagrama $T$ - $P_{\text {fluidos }}$ com a projeção das curvas de equilíbrio das reações de interesse para o estabelecimento das condições metamórficas atuantes nos Complexos de Mangabal I e II

Figure 9 - Calculated P-T conditions for parageneses observed in rocks of Mangabal I and $\mathrm{n}$ and isochores of $\mathrm{CO}_{2}$ for densities determined in fluid inclusions. The most probable P-T conditions are outlined

Tabela 2 - Equações das reações das figuras 8 e 9 Table 2 - Reations and equations of figures 8 and 9

\begin{tabular}{|c|c|}
\hline (4) & $\begin{array}{l}7 \mathrm{En}+1 \mathrm{mgParg}+1 \mathrm{Ep}=(2 \mathrm{An}+1 \mathrm{Ab})+6 \mathrm{Fo}+\mathrm{H}_{2} \mathrm{O} \\
\log \mathrm{K}=\log \mathrm{f}_{\mathrm{H}_{2} \mathrm{O}}=-\frac{14007}{\mathrm{~T}}+11,996-0,168 \frac{(\mathrm{P}-1)}{\mathrm{T}}\end{array}$ \\
\hline (5) & $\begin{array}{l}7 \text { Ens Fs20 }+1 \text { mgPargso fePargzo }+1 \text { Espso Hc20 }= \\
(2 \mathrm{An}+1 \mathrm{Ab})+6 \mathrm{Fos0}_{30} \mathrm{Faz0}_{20}+\mathrm{H}_{2} \mathrm{O} \\
\log \mathrm{X}=\log \mathrm{fH}_{2} \mathrm{O}=-\frac{12882}{\mathrm{~T}}+11,644-0,165 \frac{(\mathrm{P}-1)}{\mathrm{T}}\end{array}$ \\
\hline (6) & $\begin{array}{l}7 \mathrm{~F}+1 \mathrm{feParg}+1 \mathrm{Hc}-(2 \mathrm{An}+1 \mathrm{Ab})+6 \mathrm{Fa}+\mathrm{H}_{2} \mathrm{O} \\
10 \mathrm{~K}=\log \mathrm{ftz}_{2} \mathrm{O}=-\frac{8393}{\mathrm{~T}}+10,238-0,150 \frac{(\mathrm{P}-1)}{\mathrm{T}}\end{array}$ \\
\hline (7) & $\begin{array}{l}1 \mathrm{Anto}+1 \mathrm{Fo}=9 \mathrm{En}+1 \mathrm{H}_{2} \mathrm{O} \\
\log \mathrm{K}=\log \mathrm{fH}_{2} \mathrm{O}=-\frac{4758}{\mathrm{~T}}+7,778+0,139 \frac{(\mathrm{P}-1)}{\mathrm{T}}\end{array}$ \\
\hline (8) & $\begin{array}{l}1 \mathrm{Clo}=1 \mathrm{Fo}+1 \mathrm{Esp}+2 \mathrm{En}+4 \mathrm{H}_{2} \mathrm{O} \\
\log \mathrm{K}=4 \log \mathrm{ft}_{20} \mathrm{O}=-\frac{14.252}{\mathrm{~T}}+26,296+0,320 \frac{(\mathrm{P}-1)}{\mathrm{T}}\end{array}$ \\
\hline (9) & $\begin{array}{l}\text { 1. Anto }=7 \mathrm{Bn}+1 \mathrm{Qz}+\mathrm{H}_{2} \mathrm{O} \\
\log \mathrm{K}=\log \mathrm{f}_{20} \mathrm{O}=-\frac{4.590}{\mathrm{~T}}+7,416+0,0119 \frac{(\mathrm{P}-1)}{\mathrm{T}}\end{array}$ \\
\hline
\end{tabular}

dos complexos, e num modelo evolutivo da fase fluida com o decorrer dos reequilíbrios mineralógicos num sistema deficiente em água, onde a fase fluida é constituída por $\mathrm{H}_{2} \mathrm{O}$ e $\mathrm{CQ}_{2}$. Neste modelo, as rochas com as parageneses mais hidratadas (associações $\mathrm{C}$ e $\mathrm{F}$, Tab. 1) representariam as associações formadas em condições de $\mathrm{P}_{\text {total }}=\mathrm{PH}_{2} \mathrm{O}$, enquanto as associações coroníticas e com espinélio (associações A, B, $\mathrm{D}, \mathrm{E}, \mathrm{Tab}$. 1), bem como as que ainda preservam feições magmáticas reliquiares representariam as associações reequilibradas em condições de $\mathrm{P}_{\mathrm{H}_{2} \mathrm{O}}<$ Ptotal.

Dentro desta hipótese, as associações dos meta-peridotitos e meta-harzburgitos com clorita (ol + opx + magnésio homblenda + clorita) e dos meta-olivina gabronoritos (magnésio - hornblenda + . andesita + gedrita + opacos) representam as parageneses mais hidratadas desses tipos litológicos, formadas em condições de saturação em água. Para as rochas ultramáficas, os dados mineralógicos e experimentais mostram que tais associações são estáveis no campo delimitado pelas curvas (7) e (8) (Fig. 9), que marcam, respectivamente, o limite inferior de estabilidade do ortopiroxênio e o limite superior de estabilidade do clinocloro.

A presença de ortoanfibólio (da série gedrita-antofilita) nos metaolivina gabronoritos, e de antofílita, presente em metagabronoritos (rochas constituídas por magnésio-horn- 
blenda, antofilita, andesina, quartzo), tipo litológico abundante nos complexos mas não formador de coronas, permite restringir melhor o campo T-P pelas curvas (9) e (10) (Fig. 9), que marcam o limite superior de estabilidade da antofilita em função da temperatura e da pressão total do sistema, respectivamente.

O campo definido pelas curvas (7), (8), (9) e (10) (área pontilhada da Fig. 9) representa, um primeira aproximação, as condições de temperatura e pressão dos reequilíbrios das rochas dos complexos em condições de saturação em água.

Com a fixação de $\mathrm{H}_{2} \mathrm{O}$ na formação das associações hidratadas, a composição da fase fluida, em condições deficientes em $\mathrm{H}_{2} \mathrm{O}$, deverá passar a apresentar valores de $\mathrm{P}_{\mathrm{H}_{2} \mathrm{O}}$ relativamente inferiores a $\mathrm{P}_{\text {total }}$. Como observado, a transição entre associações mais hidratadas e as coroníticas e/ou reliquiares é relativamente rápida, indicando que $\mathrm{o}$ valor de $\mathrm{P}_{2} \mathrm{O}$ na fase fluida deve decair rapidamente. Em condições de $\mathrm{P}_{\mathrm{H}_{2} \mathrm{O}}<\mathrm{P}_{\text {total }}$, as reações coroníticas ocorrem em temperaturas significativamente inferiores às expressas pela curva (5), como exemplificado pelas curvas $(5 a),(5 b)$ e (5c) (Fig. 9), calculadas para diferentes valores de $\mathrm{P}_{\mathrm{H}_{2} \mathrm{O}}$ (Althaus 1968).

Pelas condições de T-P previamente delimitadas, as associações coroníticas devem ter sido desenvolvidas em condições de $\mathrm{PHP}<\mathrm{PT}$, pois a presença de espinélio nestas associações é limitada pela curva (8) ou $8 \mathrm{a}, 8 \mathrm{~b}$, em função de $\mathrm{X}_{\mathrm{H} 2} \mathrm{O}$ (Fig. 9).

A evolução das coronas leva, assim, a uma diminuição contínua de $\mathrm{P}_{2} \mathrm{O}$ e concomitante aumento de $\mathrm{P}_{\mathrm{CO}_{2}}$ na fase fluida. $\mathrm{O}$ sistema deve evoluir até que o valor de $\mathrm{P}_{\mathrm{H}_{2} \mathrm{O}}$ na fase fluida não seja mais suficiente para o prosseguimento das reações, restando uma fase fluida significativamente rica em $\mathrm{CO}_{2}$. Esse aspecto é registrado nas rochas estudadas, seja pela formação de dolomita nas partes mais externas da corona, seja pela natureza das inclusões fluidas aprisionadas em plagioclásios recristalizados, constituídas essencialmente por $\mathrm{CO}_{2}$. $\mathrm{O} \mathrm{CO}_{2}$ presente nestas inclusões representa, neste modelo evolutivo, a composição da fase fluida no final das reações coroníticas, aprisionada no plagioclásio quando da recristalização desse mineral. Nesse contexto, os dados das inclusões fluidas possibilitam deduzir as condições de pressão total do sistema (Touret 1977, 1981), visto já se conhecer o campo de temperatura dos reequilíbrios (Fig. 9).

$\mathrm{O}$ estudo das inclusões fluidas foi realizado por um dos autores (RASG), no Laboratório de Inclusões Fluidas da Universidade de Paris VII O conjunto dos dados rnicrotermométricos mostra que a temperatura de homogeneização (Th) da fase fluida apresenta uma variação de $-27^{\circ} \mathrm{C}$ a $-18^{\circ} \mathrm{C}$, com um máximo entre $-22^{\circ} /-25^{\circ} \mathrm{C}$. Tais temperaturas fornecem densidades para $\mathrm{o}_{\mathrm{CO}_{2}}$ variando de $1,02 \mathrm{~g} / \mathrm{cm}^{3}$ $\left(\mathrm{Th}=-18^{\circ} \mathrm{C}\right)$ a $1,075 \mathrm{~g} / \mathrm{cm}^{3}\left(\mathrm{Th}=-27^{\circ} \mathrm{C}\right)$, com valor médio de densidade correspondente a $1,05 \mathrm{~g} / \mathrm{em}^{3}$ para as temperaturas no ponto de máxima $\left(\mathrm{Th}=-25^{\circ} \mathrm{C}\right.$ (Hollister 1981).

As isócoras do $\mathrm{CO}_{2}$ correspondentes às densidades das ordens de $1,10 \mathrm{~g} / \mathrm{cm}^{3}, 1,05 \mathrm{~g} / \mathrm{cm}^{3}$ e $1,00 \mathrm{~g} / \mathrm{cm}^{3}$ encontram-se projetadas na figura 9 , nas curvas a, b, c (ou a', b' e c') respectivamente (dados extraídos de Shmonov \& Shmulovich 1974), e definem as condições de T-P nas quais o $\mathrm{CO}_{2}$ apresenta tais densidades.

$\mathrm{A}$ isócora de $\mathrm{CO}_{2}$, correspondente à de densidade da ordem de $1,05 \mathrm{~g} / \mathrm{cm}$ (curva b ou b'), intercepta o campo de temperaturas limitado pelas curvas (7) e (9) a pressões da ordem de 6,0 e 6,5 kbar, pouco abaixo da curva (10), limite de estabilidade da antofilita em função da pressão. Tal interceptação define o campo de temperaturas (entre as curvas 7 e 9) e de pressão (limitado pela isócora do $\mathrm{CO}_{2}$ para $\mathrm{d}=1,05 \mathrm{~g} / \mathrm{cm}$ e pela curva 10 ) representativo das condições atuantes nos reequilíbrios metamorficos dos complexos (campo hachurado, Fig. 9). As reações coroníticas devem ter ocorrido quanòb o valor de $\mathrm{P}_{\mathrm{H}_{2}} \mathrm{O}$ na fase fluida atingiu valores da ordem de $1 \mathrm{kbar}$, como indicado pela curva $(5 \mathrm{~b})$, correspondente à curva $(5)$, quando $\mathrm{P}_{2} \mathrm{O}$ representa em tomo de $20 \%$ da fase fluida $\left(\mathrm{X}_{\mathrm{H}_{2} \mathrm{O}} \leq 0,2\right.$ e $\left.\mathrm{Xco}_{2} \geq 0,8\right)$. Para estes valores de $\mathrm{P}_{\mathrm{H}_{2} \mathrm{O}}$, a curva (8) desloca-se para temperaturas inferiores (curvas 8a, 8b - Fig. 9) e, assim, as associações coroníticas ou com espinélio passam a situar-se em pleno campo de estabilidade.

Este modelo explica satisfatoriamente a diversidade de assembléias mineralógicas constatadas nos complexos. Todas as associações são estáveis em condições de $750 \pm 50^{\circ} \mathrm{C}$ e pressão de 6,5 $\pm 0,5 \mathrm{kbar}$, sendo a diversidade das associações devida à variação em $\mathrm{P}_{\mathrm{H}_{2} \mathrm{O}}$ presente na fase fluida quando dos reequilíbrios minerais. Nas partes em que houve saturação em água, desenvolveram-se as associações hidratadas; a presença de coronas em diferentes estágios de evolução é resultante de variações discretas no valor de $\mathrm{P}_{\mathrm{H}_{2}} \mathrm{O}$ na fase fluida já empobrecida em água.

CONCLUSÕES O modelo exposto neste trabalho, envolvendo a formação conjunta de assembléias coroníticas e hidratadas, com base nos dados cristaloquímicos, petrográficos e termodinâmicos, mostra-se plenamente coerente com todas as evidências disponíveis na petrograf ia e geologia dos corpos estudados.

Numa consideração isolada dos dados modais das rochas, mostrando associações anidras e fortemente hidratadas, é possível inferir que as associações coroníticas teriam sido geradas num primeiro evento térmico, seja ligado a processos pósmagmáticos ou de metamorfismo de alto grau, enquanto as associações desenvolvidas em metaperidotitos e meta-harzburgitos com clorita teriam sido equilibradas num evento térmico posterior, mais brando (fácies anfibolito). Entretanto, não há evidências estruturais e texturais nos corpos e nas rochas encaixantes que sustentem a hipótese de dois eventos térmicos. As evidências texturais registradas nas rochas coroníticas excluem, ao mesmo tempo, a possibilidade de sua formação estar vinculada aos estágios finais de processos magmáticos (Sapountzis 1975, Lamoen 1979, Emmett 1982). Nas amostras analisadas, não se constatou a presença de feições de deformação nas coronas, mesmo naquelas nas quais os plagioclásios originais mostram sinais de deformação (cristais quebrados, com extinção ondulante, com lamelas de geminação encurvadas etc).

A estruturação dos corpos mostra sinais claros de que, entre o estágio magmático e a formação das coronas, interpõe-se uma fase de deformação tectônica de larga escala, o que estabelece um hiato temporal entre a fase magmática e a coronítica/metamórfica. Sendo assim, é pouco provável a formação de coronas por processos imediatamente pós-magmáticos, sendo sua formação mais coerentemente ligada a processos metamorficos.

A origem metamórfica das coronas foi contestada por muito tempo, em vários trabalhos. Entretanto, estudos mais recentes (Mork 1986) mostram a formação de coronas não-deformadas de origem indubitavelmente metamórfica. Por datações geocronológicas foi constatado que as coronas presentes em eclogitos derivados de olivina gabros da Noruega formaram-se em ciclos e processos geológicos distintos, desvinculados do evento magmático formador dos corpos.

Nos complexos em estudo, o conjunto de rochas mostras deformação e recristalização e, localmente, foliações intensas, com núcleos e partes menos ou não-deformadas, onde as coronas são desenvolvidas. A penetração diferencial da fase fluida pode ser considerada o agente formador de associações anidras e hidratadas em condições metamórficas num pico térmico posterior à fase deformacional.

Agradecimentos Os autores agradecem à Metais de Goiás SÁ. (METAGO), que nos facultou estudar a área; e à FINEP, FAPESP e CNPq, pelo auxílio financeiro. 


\section{REFERÊNCIAS BIBLIOGRÁFICAS}

ALMEIDA, F.F.M. 1968. Evolução tectônica do centro-oeste brasileiro no Proterozóico superior. An. Acad. bras. Ciênc., 40(Supl.):285-295.

ALTHAUS, E. 1968. Der Einflu des Wassers auf metamorphe mineral-reaktionen. $N$. Jb. Miner. Mh., 9:289-306.

BROWN, GE., Jr. 1980. Olivines and silicate spinels. In: RISE, RH. ed Orthossilicates. Reviews in Mineralogy Miner. Soc. Am., 5:275-298.

CANDIA, M.A.F. 1983. Petrologia dos complexos máfico-ultramáficos de Mangabal I e Mangabal II, Sanclerlândia, Goiás. São Paulo. 400 p. (Tese de doutoramento, IG/USP)

CANDIA, M.A.F. \& GIRARDI, VA.V. 1985. Geologia e petrologia dos complexos máfico-ultramáficos de Mangabal I e Mangabal n, Goiás. Rev Bras. Geoc. 15(3):221-230.

DEER, W.A., HOWffi, R.A. e ZUSSMAN, J. 1977. An introduction to the rock-forming minerals. London, Longman. 528 p.

EMMETT, T.F. 1982. The petrography and geochemistry of corona-bearing dolerites from the Jotun Nappe, Central Southern Norway. Mineral Mag., 46:43-48

ESBENSEN, K.H. 1978. Coronites from the Fongen gabbro complex, Trondheim Region, Norway: role of water in the olivine-plagioclase reaction. N. Jb. Mineral Abh. 132(2): 113-135.

EVANS, B.W. 1982. Amphiboles in metamorphosed ultramaphic rocks. In: VEBLEN, D.R. \& RIBBE, P.H. ed Amphiboles: Petrology and Experimental Phase Relations. Reviews in Mineralogy, 9B:98-112.

FISHER, J.R. \& ZEN, E. 1971. Thermochemical calculations from hydrotermal phase equilibrium data and the free energy of $\mathrm{H}_{2} \mathrm{O} . A m$. J. Sci, 270:297-314.

FROST, B.R. 1975. Contact metamorphism of serpentinite, chloritic blackwall and rodingite at Paddy - Go - Easy Pass, Central Cascades, Washington. J. Petrol. 16:272-313.

GARDNER, P.M. \& ROBINS, B. 1974. The olivine-plagioclase reaction: geological evidence from the Seilandpetrographic province. Contr. Min. Petrol, 44:149-156.

GILBERT, M.C. 1966. Synthesis and stability reactions of the hornblende ferropargasite. Am. J. Sci., 264:698-742.

GRIEVE, R.A \& GITTINS, J. 1975. Composition and formation of coronas in the Hadlington gabbro, Ontario, Canada. Can. J. Earth. Sci., 12:289-299.

GRIFFIN, W.L. \& HEEER, K.S. 1973. Petrological implications of some corona structures. Lithos, 6:315-335.

HAMLYN, P. 1980. Equilibration history and phase chemistry of the Panton Sill, Western Australia. Am. J. Sci., 280:631-668.

HELGESON, H.C.; DELANEY, JJM.; NESBITT, H.W.; BIRD, D.K. 1978. Summary and critique of the thermodynamic properties of rock-forming minerals. Am. J. Sci., 278-A:229 p.

HOLLISTER, L.S. 1981. Information intrinsically available from fluid inclusions. In: HOLLISTER, L.S. \& CRAWFORD, M.L. ed. Short Course in fluid inclusions: applications to petrology. Calgary, Mineralogical Association of Canada, p. 1-12.

IRVINE, T.N. 1982. Terminology for layered intrusions. J. Petrol, 23:127-162.

LAMOEN, H. Van 1979. Coronas in olivine gabbro and iron ores from Susimaki and Riuttamaa, Finland. Contr. Min. Petrol, 68:259-268.

LEAKE, B.E. 1978. Nomenclature of amphiboles. Am, Miner., 63:1023-1052.

MILLER, C. 1974. Reactions rims between olivine and plagioclase in metaperidotites, Ozztal Alps, Austria. Contr. Min. Petrol, 43:333-342.

MONGKOLTIP, P. \& ASHWORTH, J.R. 1983. Quantitative estimation of an open-system sympectite-forming reaction: restricted diffusion of Al and $\mathrm{Si}$ in coronas around olivine. J. Petrol, 24:635-661.
MORK, M.B.E. 1986. Coronite and eclogite formation in olivine gabbro (Western Norway): reaction paths and garnet zoning. Mineral Mag. 50:417-426.

MURTHY, M. V.N. 1958. Coronites from India and their bearing on the origin of coronas. Bull Geol Soc. Am., 68:23-38.

NEWTON, R.C.; CHARLU, T.V.; KLEPPA, O.J. 1980. Thermochemistry of the high structural state plagioclases. Geochim. Cosmochim. Acta, 44:933-941.

NILSON, A.A. 1984. O atual estágio de conhecimento dos complexos máficos-ultramáficos pré-cambnanos do Brasil - Uma avaliação preliminar. In: CONOR. BRÁS. GEOL., 33. Rio de Janeiro, 1984. Anais..., Rio de Janeiro, SBG. v. 9, p. 4166-4203.

NISfflYAMA, T. 1983. Steady diffusion model for olivine-plagioclase corona grouth. Geochim. Cosmochim. Acta, 47:283-294.

ROBIE, R.A.; HEMINGWAY, B.S.; FISHER, J.R. 1978. Thermodyriamic properties of minerals and related substances at $298.15 \mathrm{~K}$ and $1 \mathrm{bar}$ (10 Pascal) pressure and at higher temperatures. Geol Sum Bull, 1452:456 p

ROBINS, B. \& GARDNER, P.M. 1974. Synorogenetic layered basic intrusions in the Seiland petrographic province, Finmark. Norges Geol, Unders. 312:91-130.

ROBINSON, P.; ROSS, M.; JAFFE, H.W. 1971. Composition of the anthophyllite-gedrite series, comparisons of gedrite and hornblende, and the anthophyllite-gedrite solvus. Am. Mineral, 56:1005-1041.

ROBINSON, P.; SPEAR, F.S.; SCHUMACHER, J.C.; LAIRD, J.; KLEIN, C; EVANS, B.W.; DOOLAN, B.L. 1982. Phase relations of metamorphic amphiboles: natural occurrence and theory. In: VEBLEN, D.R. \& RIBBE, P.H. eds. Amphiboles: petrology and experimental phase relations Reviews in Mineralogy, v. 9B. Mineral Soc. Amer. Washington.

RYZHENKO, B.N. VOLKOV, V.P. 1971. Fugacity coefficients of some gase in a broad range of temperatures and pressures. Geochem. Intern., 468-481.

SAPOUNTZIS, E.S. 1975. Coronas from the Thessaloniki gabbros (North Greece). Contr. Min. Petrol, 51:197-203.

SHMONOV, V.M \& SHMULOVICH, K.I. 1974. Molar volumes and equations of state for $\mathrm{COz}$ at $100-1000^{\circ} \mathrm{C}$ and $2.000-10.000 \mathrm{bar}$ AkadNauk. URSS, Dokl, 212:936-938.

SIMKIN, T. \& SMITH, J.V. 1970. Minor element distribution in olivine. J. Geol, 78:304-325.

TOURET, J. 1977. The significance of fluid inclusions in metamorphic rocks. In: FRASER, D.G. ed. Thermodynamics in Geology. Reidel Publishing Company, p. 203-227.

TOURET, J. 1981. Fluid inclusions in high-grade metamorphic rocks. In HOLLISTER, L.S. \& CRAWFORD, M.L. ed, Short Course in fluid inclusions: applications to petrology. Calgary, Mineralogical Association of Canada, p. 182-208

WAGER, L.R., BROWN, G.M. \& WADSWORTH, W.J. 1960. Types of igneous cumulates. J. Petrol, 1:77-85.

WESTRICH, H.R. \& HOLLOWAY, J R. 1981. Experimental dehydration of pargasite and calculation of its entropy and Gibbs energy. Am. J. Sci., 281:922-934.
Manuscrito A688

Recebido em 24 de janeiro de 1991 Revisão do autor em 7 de outubro de 1991 Revisão aceita em 20 de novembro de 1991 